\title{
The spine in Paget's disease
}

\author{
C. Dell'Atti • V. N. Cassar-Pullicino • R. K. Lalam • \\ B. J. Tins • P. N. M. Tyrrell
}

Received: 30 October 2006 /Revised: 18 December 2006 / Accepted: 22 December 2006 / Published online: 5 April 2007

(C) ISS 2007

\begin{abstract}
Paget's disease (PD) is a chronic metabolically active bone disease, characterized by a disturbance in bone modelling and remodelling due to an increase in osteoblastic and osteoclastic activity. The vertebra is the second most commonly affected site. This article reviews the various spinal pathomechanisms and osseous dynamics involved in producing the varied imaging appearances and their clinical relevance. Advanced imaging of osseous, articular and bone marrow manifestations of PD in all the vertebral components are presented. Pagetic changes often result in clinical symptoms including back pain, spinal stenosis and neural dysfunction. Various pathological complications due to PD involvement result in these clinical symptoms. Recognition of the imaging manifestations of spinal PD and the potential complications that cause the clinical symptoms enables accurate assessment of patients prior to appropriate management.
\end{abstract}

Keywords Paget's disease - Vertebra - Spinal stenosis . Magnetic resonance imaging $\cdot$ Computed tomography

\section{Introduction}

Paget's disease (PD) or osteitis deformans is one of the commonest metabolically active bone diseases, second in prevalence only to osteoporosis, characterised by a disturbance in bone modelling and remodelling because of an increase in osteoblastic and osteoclastic activity. It is more

C. Dell'Atti • V. N. Cassar-Pullicino $(\bowtie) \cdot$ R. K. Lalam •

B. J. Tins • P. N. M. Tyrrell

Department of Radiology, Robert Jones and Agnes Hunt

Orthopaedic and District Hospital,

Oswestry SY10 7AG, UK

e-mail: Victor.Pullicino@rjah.nhs.uk common in people of Anglo Saxon origin and is less common in the Far East, India, Middle East and Africa. The overall prevalence of PD is 3-3.7\% and increases with age [1-3]. By the age of 90 years, the prevalence increases to about $10 \%$ [2]. As the aetiology of PD continues to be the subject of debate, it is variously classified as an infection, metabolic disorder and a neoplastic process [1, 4-15]. However, strictly speaking, as the unaffected skeleton is metabolically normal, it does not fulfil the criteria for a true metabolic bone disorder.

The epidemiology of PD shows some significant changing trends in the clinical profilometry. First, recent studies have demonstrated that the incidence and prevalence of PD is gradually declining [16-18]. Second, there is a general trend towards reduction in the severity of the disease as measured by serum alkaline phosphatase levels $[19,20]$. Third, there is a steady increase in the age at presentation by about 4 years per decade [18] and last, the proportion of patients with monostotic disease is increasing [18]. This in turn means that we are likely to see a higher incidence of monostotic vertebral involvement in the future.

The spine is the second most commonly affected site (53\%) [6], after the pelvis (70\%) [21-23]. The disease is polyostotic in $66 \%$ of cases and between $35 \%$ [24, 25] and $50 \%[7,8]$ have spinal involvement. Using multimodal advanced imaging, this review article focuses on the pathological processes that underlie the varied spinal manifestations and complications of PD.

\section{Pathomechanisms}

In PD the loss of homeostatic control leads to increased osteoblastic and osteoclastic activity and constitutes the background for the main three phases. The initial lytic 
phase represents a mainly osteoclastic activity, the late osteoblastic phase is characterised by new bone formation, while the intervening mixed phase is seen when there is a combination of osteoblastic and osteoclastic activities [24, 26]. One more phase, "inactive sclerotic phase", characterised by normal or decreased bone activity, has also been described [5], when the stimulation of new osteoblast and osteoclast formation ceases. Although the bone is metabolically inactive, it maintains a sclerotic coarsened architecture [27]. In bones with a low trabecular/cortex ratio like the skull, femur and humerus, the early lytic phase is radiologically depicted by a clear leading edge at the interface with normal bone. The lytic phase is usually not detected in bones with a high trabecular/cortex ratio like the vertebra, sacrum and pelvis [28]. Vertebral body involvement at radiological diagnosis is virtually always complete, and therefore the leading edge present in the other affected bones is not seen in the vertebra [29]. These phases can be evident in the same patient and at the same time in different bones including the vertebral column. Although progression of disease occurs within an affected bone, the sudden appearance of bone involvement at new skeletal sites years after the initial diagnosis is uncommon [30, 31].

The pathomechanisms and the dynamics involved in bone remodelling in PD of the appendicular and axial skeleton at the periosteal and endosteal surfaces have been previously described $[3,5,32]$. The enhanced abnormal osteoblastic activity results in periosteal and endosteal new bone formation (apposition). The abnormal osteoclastic activity on the endosteal surface results in bone resorption (absorption). The various combinations of these mechanisms give rise to four different patterns of bone remodelling at the periosteum/endosteal interface leading to bone enlargement: periosteal and endosteal apposition; periosteal apposition and endosteal absorption; periosteal apposition with normal endosteal surface; and focal periosteal apposition - "pumice stone" appearance (Figs. 1, 2). The mechanisms in the spine commonly responsible for the changes on the periosteal and endosteal surfaces of the vertebral body and posterior neural arches are varied (Figs. 1, 2, 3, 4). These various mechanisms are not exclusive of each other, but can occur in combination in the same vertebra at various borders. Usually, one of the pathomechanisms predominates in the involved vertebra. The most frequent mechanism of vertebral body expansion is periosteal apposition and endosteal absorption. The new bone formation predominates on the periosteal surface and it is responsible for the vertebral body enlargement, while the absorption on the endosteum results in an increased bone marrow space. Periosteal/endosteal apposition and periosteal apposition with normal endosteal surface are two less common remodelling mechanisms seen in the vertebral body. In both, the apposition on the periosteal side results in vertebral body enlargement, but the bone marrow space is decreased or normal in size respectively. The least common mechanism of vertebral body expansion is focal periosteal apposition giving the "pumice stone" appearance (Figs. 1, 2). Expansion of the vertebral bodies seen radiologically occurs in $63 \%$ of cases [25]. The commonest mechanisms in neural arch involvement are a combination involving periosteal and endosteal apposition or periosteal apposition and endosteal absorption (Figs. 3, 4). In both of the mechanisms, the periosteal apposition causes a decrease in the size of the spinal canal resulting in spinal stenosis.

\section{Imaging manifestations}

Paget's disease of the spine can either involve a single level or more than one level. The lumbar spine and more commonly the L4 and L5 levels are the most frequently involved sites (58\%) [33], more so than the thoracic (45\%) and the cervical vertebrae (14\%; Fig. 5) [8, 23]. Involvement of the atlanto-axial region is very rare $[8,34,35]$. The vertebral body is almost always involved together with a variable portion of the neural arch. Isolated involvement of either the neural arch or the vertebral body is evident in only a small percentage of cases [25].

\section{Osseous changes (vertebral body)}

The radiological appearance of vertebral body expansion is characterised on radiographs by an increase in the anteroposterior and lateral vertebral dimensions. However, the height of the vertebra is unchanged. The bony vertebral end-plates are subchondral condensations of trabecular bone and do not represent true bony cortex, i.e. there is no periosteum/endosteum interface at the caudal/cranial aspect of a normal vertebra. The sagittal and lateral enlargement is due to one of the previously described pathomechanisms in the corticated portions of the vertebral body. The pathomechanisms are best appreciated on CT (Fig. 2), where the periosteal contour and the endosteal interface due to apposition and absorption are easily seen. Whatever the mechanism causing vertebral body remodelling, bone expansion is a common denominator in PD.

Usually, the earliest phase seen radiologically in the vertebra is the mixed phase. The apparently "early" radiographic appearance of vertebral body involvement in PD is thickening and hypertrophy of the trabecular bone $[36,37]$, parallel to the end plates (Fig. 6), which can appear similar to a thickened cortex. CT reconstruction images can show this thickening and hypertrophy optimally. The combination of trabecular bone hypertrophy and thickening at the end-plates with apposition/absorption on 
Fig. 1 Diagram depicting the osseous mechanisms involved in vertebral body enlargement in Paget's disease and its effect on the size of the marrow (dashed arrows) and cortex (solid arrows). A normal vertebra is depicted in the centre of the figure. a Periosteal apposition, normal endosteum resulting in thickened cortex, but with normal marrow size. b Periosteal apposition, endosteal resorption results in normal cortical thickness and an increased marrow size. c Periosteal apposition/ endosteal apposition results in a thickened cortex and reduced marrow size. d Focal periosteal apposition results in a focal "pumice stone"-like enlargement

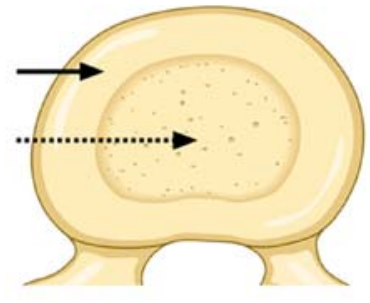

a Periosteal apposition Normal endosteum
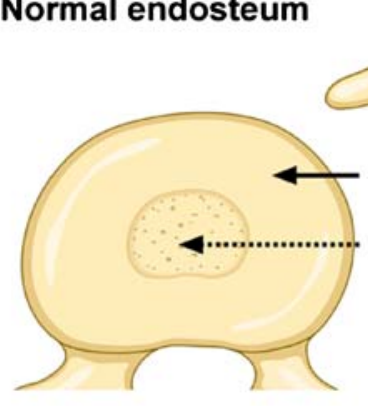

C Periosteal apposition Endosteal apposition the periosteal/endosteal surfaces at the anterior and posterior vertebral borders leads to the "picture frame" sign [36]. Radiographs demonstrate increased density in the vertebral periphery and a relatively lucent centre in the vertebral
PAGET'S DISEASE

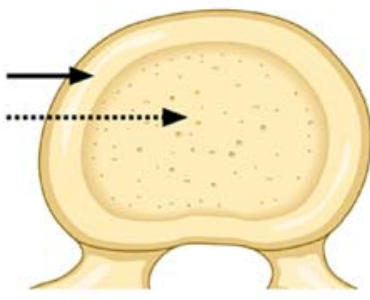

b Periosteal apposition Endosteal resorption

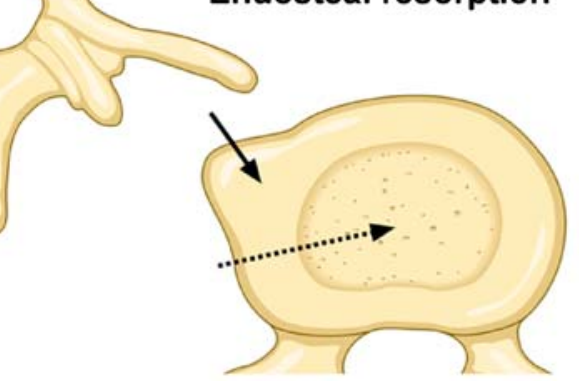

\section{d Focal Periosteal Apposition (pumice-stone)}

body [36, 38, 39], best appreciated on lateral views and on sagittal CT reconstructions (Fig. 6).

Progression of the sclerotic phase in the spine leads to "ivory vertebra", due to an increase in the density of the
Fig. 2 Axial CT sections in different patients showing the various mechanisms described in Fig. 1 and their effect on marrow size (long white arrow) and cortical thickness (short white arrow). a Periosteal apposition, normal endosteum. b Periosteal apposition, endosteal resorption. c Periosteal and endosteal apposition. d Pumice stone type (dashed arrow) of focal periosteal apposition. Similar focal periosteal apposition of the spinous process is seen
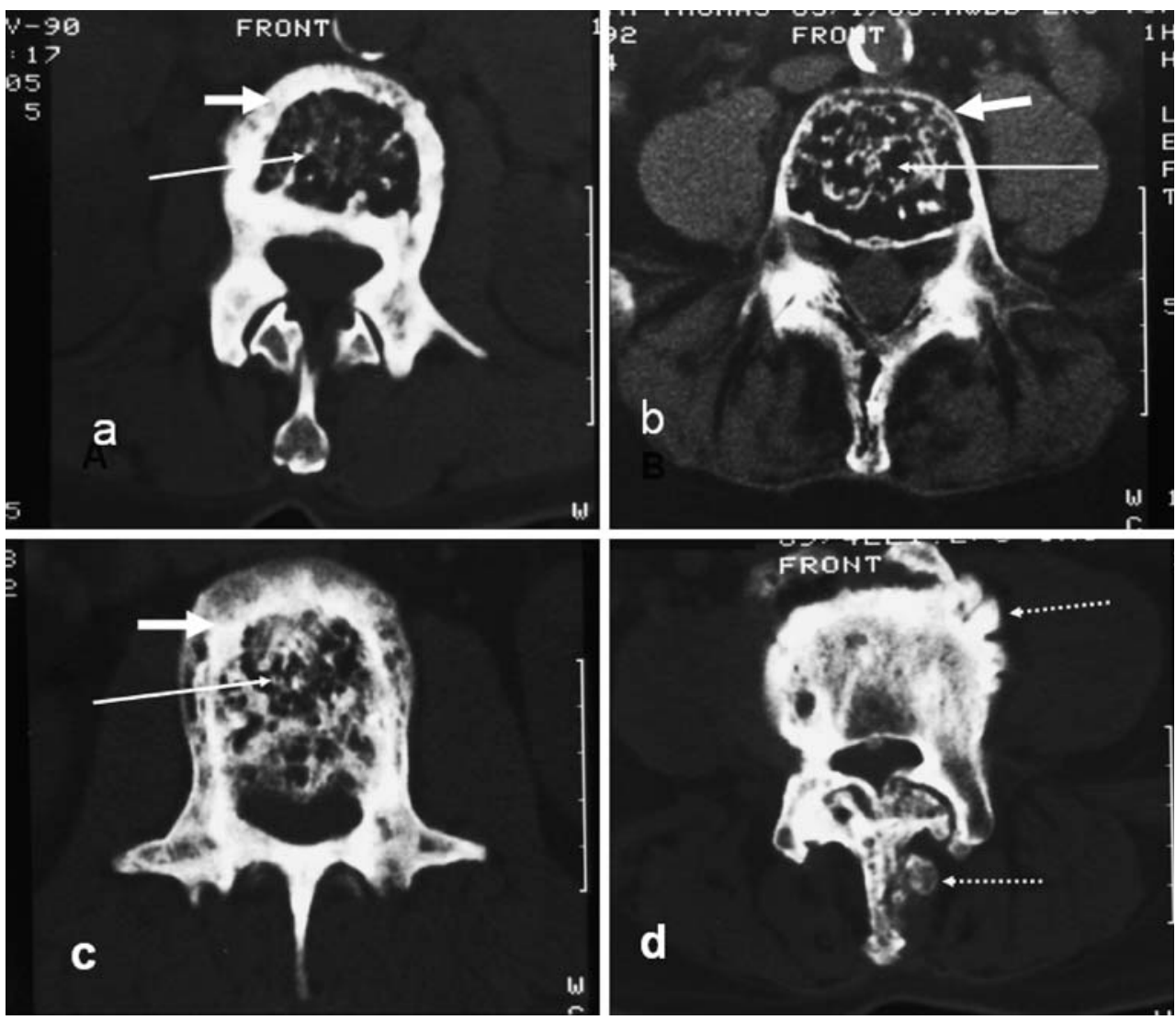
Fig. 3 Diagram showing the periosteal and endosteal Pagetic osseous mechanisms involving the cortex of the spinal canal resulting in spinal canal narrowing. Normal cortical thickness (orange) of the spinal canal (white) is depicted at the top. a Expansion of bone due to periosteal apposition/endosteal resorption results in a thin cortical outline (solid black arrow) of the narrowed spinal canal (dashed arrow). b Bony expansion due to periosteal apposition/endosteal apposition results in a thickened cortical outline (solid black arrow) of the narrowed spinal canal (dashed arrow)

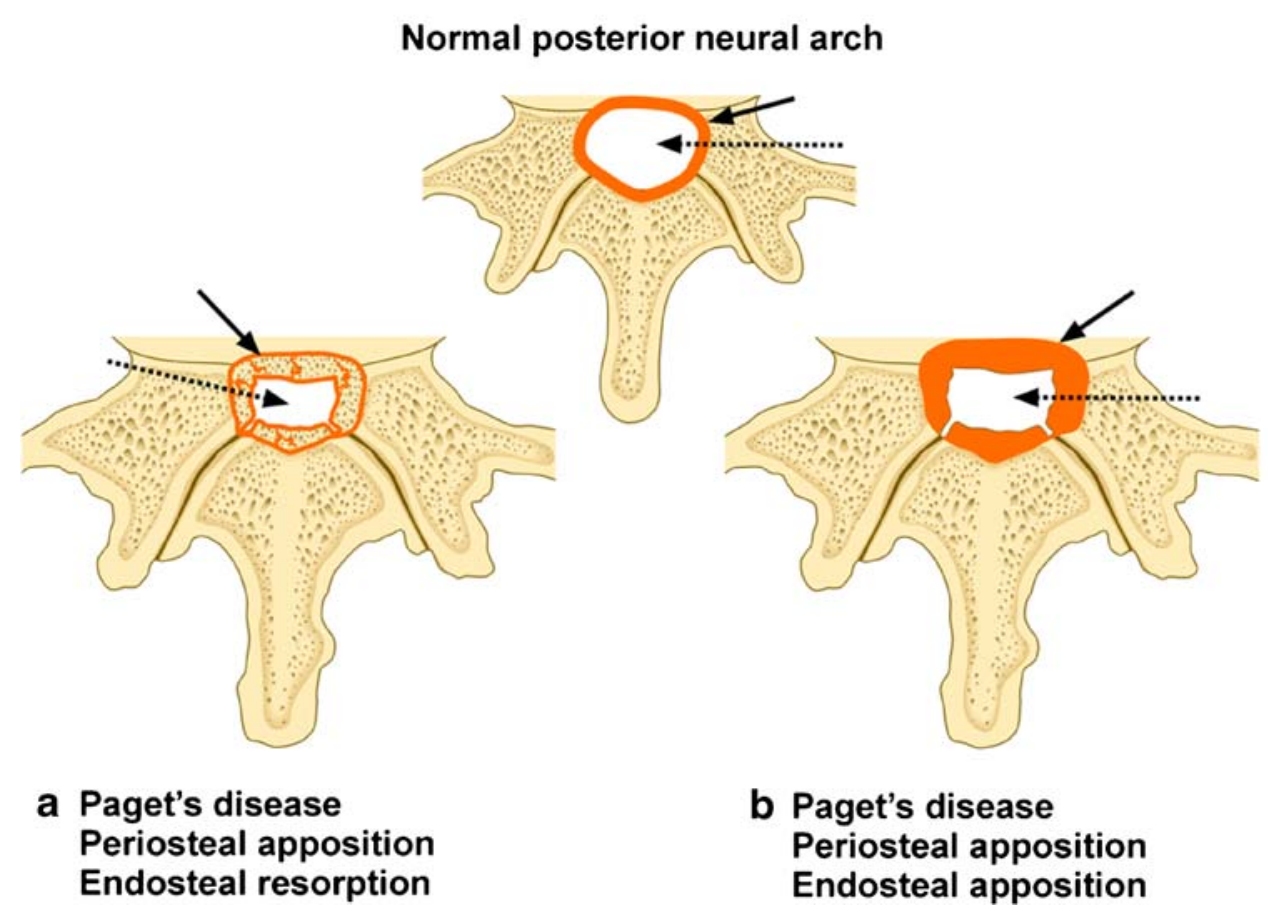


Fig. 5 Vertebral Paget's disease (PD) without expansion in two different patients. a PD of all the cervical vertebrae except C6. Note the absence of vertebral enlargement. There is sclerosis and loss of cortico-medullary differentiation of the vertebral bodies and the neural arches. b antero-posterior, c lateral radiographs and $\mathbf{d}$ axial $\mathrm{CT}$ through the L1 vertebra demonstrating sclerotic vertebra with no enlargement. The axial CT demonstrates trabecular and endosteal apposition, but no periosteal apposition accounting for the absence of enlargement. Diagnosis can be difficult and a biopsy (c) may be necessary in these cases

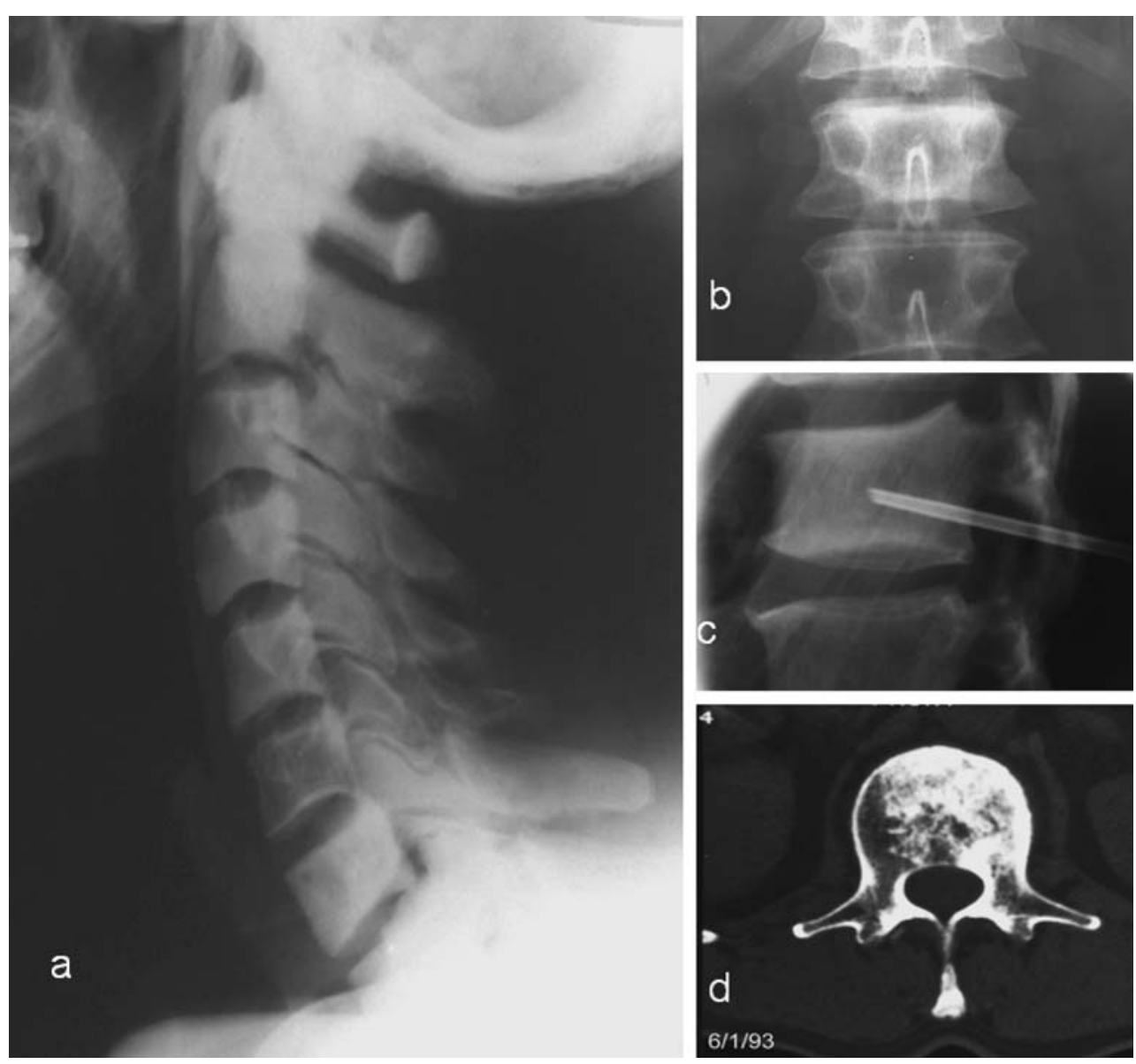

to changes in the intervening marrow space. PD of the vertebra is easily missed or misinterpreted on MR images in the early stages. This is especially true when there is an absence of classic changes including vertebral enlargement and cortical thickening. This is mainly because PD is a disorder of bone and the vertebral marrow is only secondarily affected. MRI can show discrete areas of marrow signal alteration involving vertebral bodies with
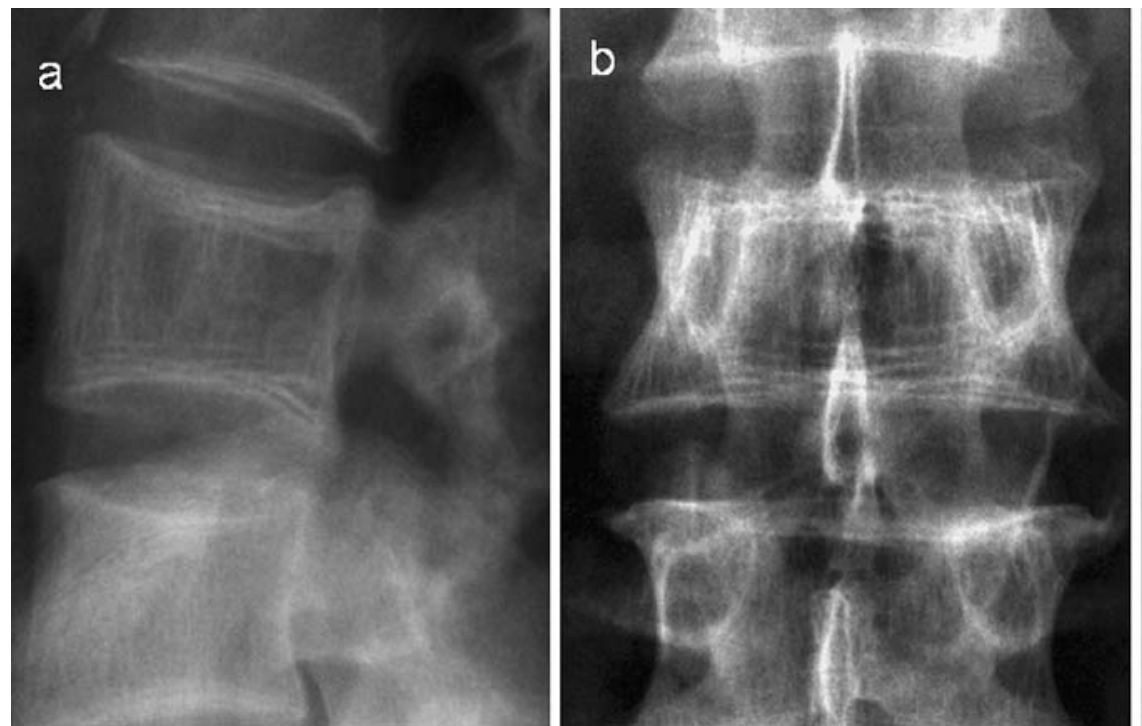

Fig. 6 a Lateral and b antero-posterior radiographs demonstrate expansion of the vertebra with characteristic sclerotic lines parallel to the end-plates due to trabecular hypertrophy, an "early" sign of PD.

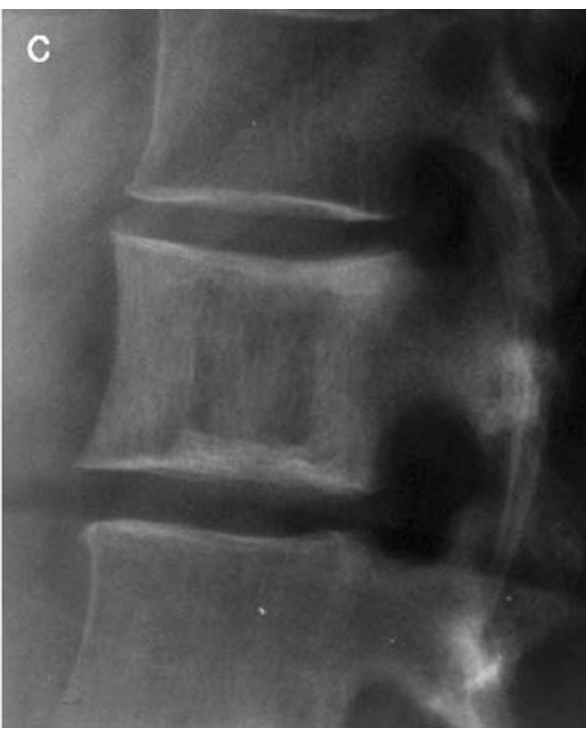

c Lateral radiograph in a different patient demonstrates the "picture frame" vertebra due to thickening of the cortex and trabecular hypertrophy at the end-plates 
low non-specific signal on T1-weighted images and high signal on T2-weighted sequences. The marrow changes due to vertebral involvement by PD are described in detail later.

\section{Osseous changes (posterior elements)}

Neural arch involvement can be difficult to evaluate on radiographs alone. The best modality for neural arch assessment is CT with reconstructions.

When periosteal and endosteal apposition occur, a markedly sclerotic cortex can be seen [5, 8]. However, when the basic mechanisms are periosteal apposition and endosteal absorption, CT demonstrates an enlarged marrow space of the neural arch delineated by a thin sclerotic line due to the periosteal apposition (Fig. 4). Both processes result in a decrease in the spinal canal diameter.

The presumed epidural fat ossification as previously described in Paget's disease [45], results in the loss of the normal MR signal of epidural fat. This is probably a consequence of expanded Pagetic bone growth out of the neural arch components towards the spinal canal, reducing its size, rather than real ossification of the epidural fat. This can be misinterpreted as epidural fat ossification on radiographs and MR imaging and is best assessed on axial CT images (Fig. 7). Sometimes, however, the fatty marrow changes in the expanded Pagetic posterior neural arch can be misinterpreted on MR imaging as epidural lipomatosis (Fig. 8). CT again helps in the correct interpretation of this situation. This emphasises the need for a combination of imaging modalities to complement each other for accurate interpretation.

Bone scintigraphy using 99-Technetium substrates and SPECT can aid the diagnosis of PD, showing a typical distribution of the disease. Scintigraphy demonstrates increased uptake in all the affected vertebral components $[46,47]$ because of its sensitivity to osteoblastic activity and can be very useful in showing activity in the posterior neural arch. As a whole body imaging modality, it also provides information about the overall distribution of the disease. Moreover, the fourth sclerotic inactive phase described by Milgram is diagnosed essentially on a bone scan where radiographically affected bone does not demonstrate increased activity due to the metabolic inactivity of the lesion [27]. However, increased activity on bone scintigraphy is usually non-specific and requires comparison with radiographs/CT. Various patterns of uptake are described on bone scintigraphy in PD [21, 46, 48, 49], all of which are non-specific.

Imaging techniques such as PET and PET-CT, can contribute to the differential diagnosis of PD from other disorders in the spine, especially when non-specific PD changes are incidentally discovered, and to assess disease activity after treatment.

In general $18 \mathrm{~F}$-fluoride positron emission tomography (PET) allows visualisation of the regional skeletal metabolic activity on the basis of the fluoride uptake on the bone surface when new bone formation and blood flow are greater [50]. The advantages of PET-CT on conventional nuclear bone scintigraphy include superior spatial resolution and more accurate quantification of bone activity. In $\mathrm{PD}$, a general increase in global skeletal blood flow, measured by fluoride deposition, is seen associated with a regional increased uptake in the affected bone. Increased activity in the pagetic bone is usually recorded almost immediately after the injection and it remains high throughout the duration of the study. However, this finding is not specific to pagetic bony changes, giving rise to some false-positives. For this reason, the combination of non-
Fig. 7 a Sagittal T1-weighted MR image demonstrates PD in the L3 vertebral body and the posterior neural arch. The low T1 signal intensity mass (arrow) replacing epidural fat can be confused with epidural ossification. b However, an axial CT image confirms this to be due to expansion of the pagetic neural arch and not to ossification of the epidural fat. There is preservation of the intra-osseous fat as seen on both the MR and CT images, a useful discriminant from malignant infiltration
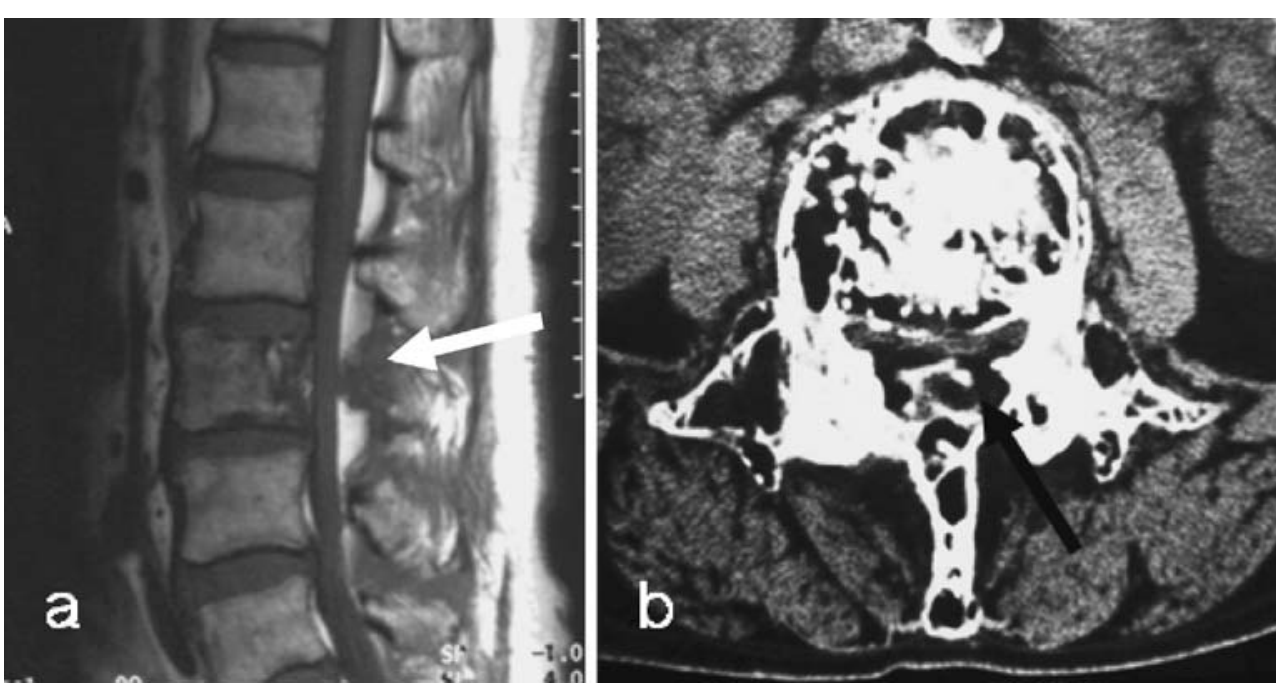

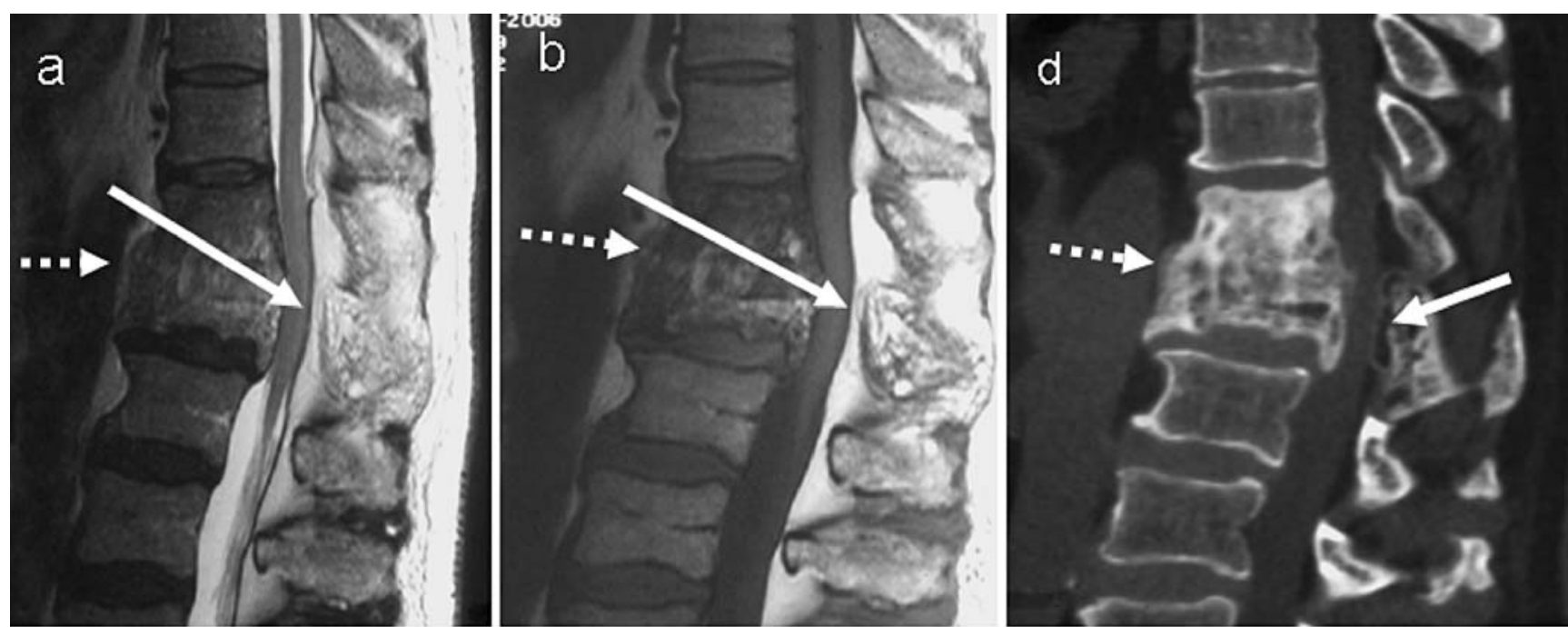

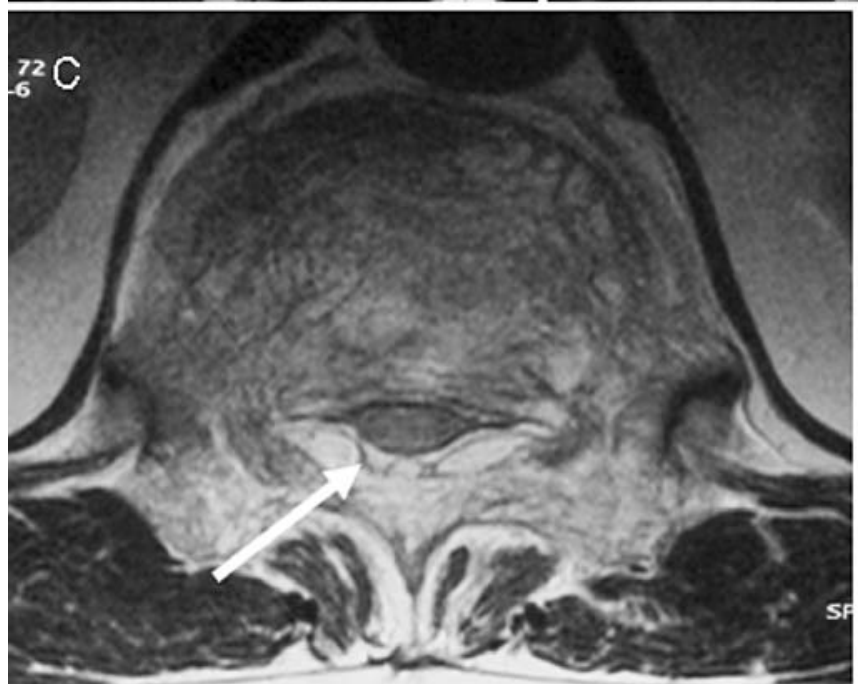

Fig. 8 Paget's disease of T11 and T12 showing an increased amount of high MR signal (solid white arrow) in the posterior epidural space at these levels on a sagittal T2-weighted, b sagittal T1-weighted and c axial T1-weighted images. This can be mistaken for epidural lipomatosis. However, the d CT sagittal and e axial images demonstrate this to be due to the fat density (solid white arrow) within the expanded posterior neural arch involved in PD. The axial

specific activity on the PET image, the findings on the CT scan (PET-CT) and the correlation with other radiological examinations increases specificity [51].

\section{Extra-osseous changes}

Paget's disease can sometimes involve the soft tissue attached to the affected vertebra including the articular cartilage, the ligaments and the intervertebral disc [26, 45].

The articular facets are commonly involved in association with vertebral body and neural arch involvement. The affected facets are enlarged and sclerotic (Fig. 9). The pagetic vertebral body involvement can interfere with the nutrition of the intervertebral disc leading to its

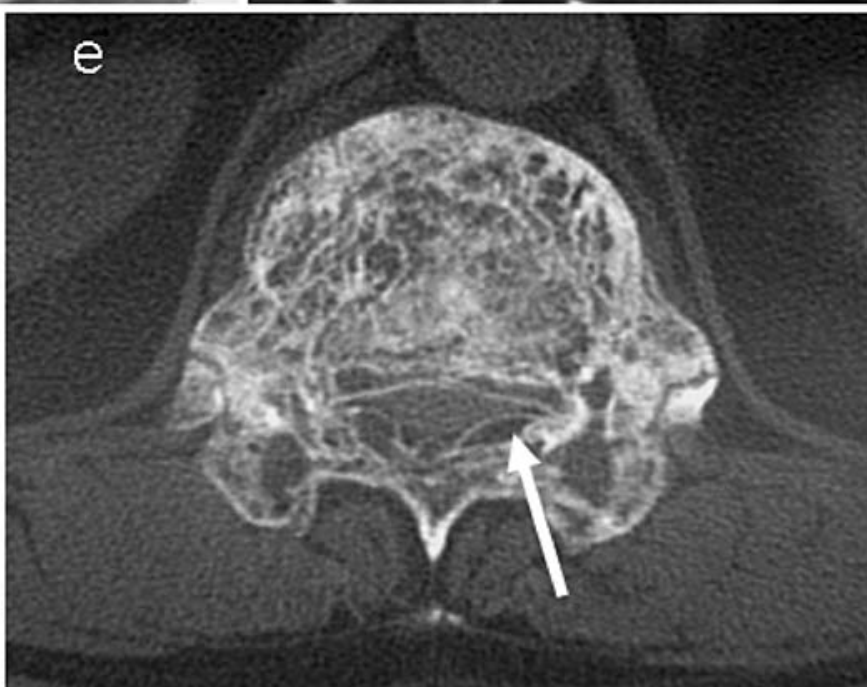

images $(\mathbf{c}, \mathbf{e})$ were obtained at the level of the tip of the solid arrows on sagittal images. There is also fusion of the vertebrae (dashed arrow) across the intervertebral disc. The combination of anterior and posterior vertebral involvement in this case resulted in severe spinal canal narrowing and cord compression. Note the high T1 signal indicating a high fatty marrow content within the pagetic T11 and T12 vertebrae

degeneration due to sclerosis adjacent to the end-plates resulting in decreased diffusion [26].

Occasionally pagetic involvement of the spine can also produce extra-osseous extension resulting in ossification of the anterior/posterior longitudinal ligaments and ligamenta flava. Lateral radiographs and CT sagittal reconstruction demonstrate the ossified anterior and posterior longitudinal ligaments. The ligamenta flava ossification are seen on the AP view as radio-opacities adjacent to the facet joints. Paravertebral soft tissue swelling seen radiographically or by $\mathrm{CT}$ can be due to extra-medullary haematopoiesis. When PD of spine results in extra-medullary haematopoiesis [52], there is extra-osseous soft tissue with signal characteristics similar to the adjacent vertebral marrow. CT and MRI 
Fig. 9 Facet involvement. a Axial CT section demonstrates incongruity at the facet joint (solid white arrow) due to an involved enlarged facet of one vertebra articulating with an uninvolved non-expanded adjacent vertebral facet. b Axial CT section in a different patient demonstrates advanced facet joint arthropathy (dashed white arrows) across two pagetic facets with complete loss of joint space and new bone formation contributing to spinal canal stenosis. This can progress to fusion across the facet joints
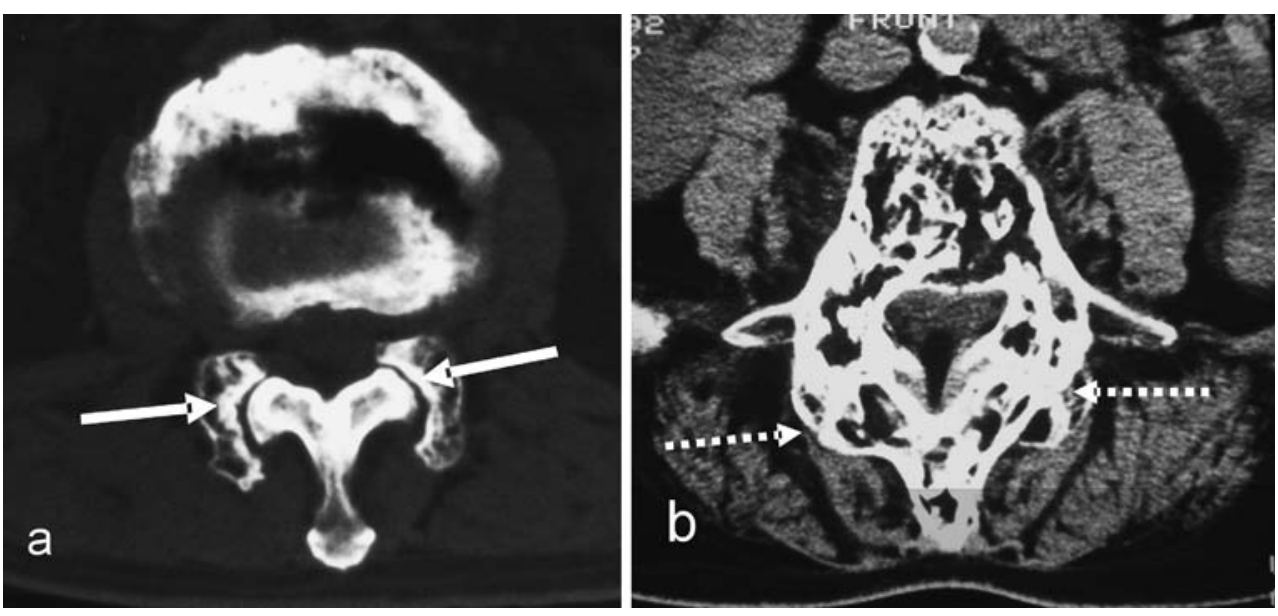

demonstrate the soft tissue mass adjacent to the vertebral body (see Pathological complications) in communication with the bone marrow within the vertebra [52].

\section{Bone marrow}

Paget's disease is primarily a disorder of bone and not of the bone marrow. Secondary bone marrow changes do, however, occur. The marrow signal changes in established Paget's disease have been well described and vary with the stage of the disease [53]. Low signal on T1-weighted images and mild high signal on T2-weighted images (Fig. 8) in the mixed hypervascular phase are seen. The sclerotic phase of PD results in low signal on both T1- and T2-weighted images in the vertebra due to increased trabecular thickness, sclerosis and marrow fibrosis (Fig. 10). There is fatty transformation in the latter stages when there is high signal on both T1- and T2-weighted images (Fig. 11). In the presence of osteolysis in pagetic vertebrae, a fat signal within the lesion is a useful clinical determinant between conservative management and biopsy in cases in which malignancy is suspected radiographically [54].

Whenever vertebral bone marrow signal changes are seen on MRI, PD has to be considered in the differential diagnosis because of its non-specific and varied appearance in the bone marrow, and subtle bony alterations suggestive of PD have to be sought. Paget's disease can, however, also coexist with other disorders.

When the bone marrow is not or only minimally involved (Fig. 12) in PD, MRI will not reveal an appreciably altered signal on either T1- or T2-weighted images. The seemingly normal MR appearance of the vertebra does not exclude PD, but affirms only the normal

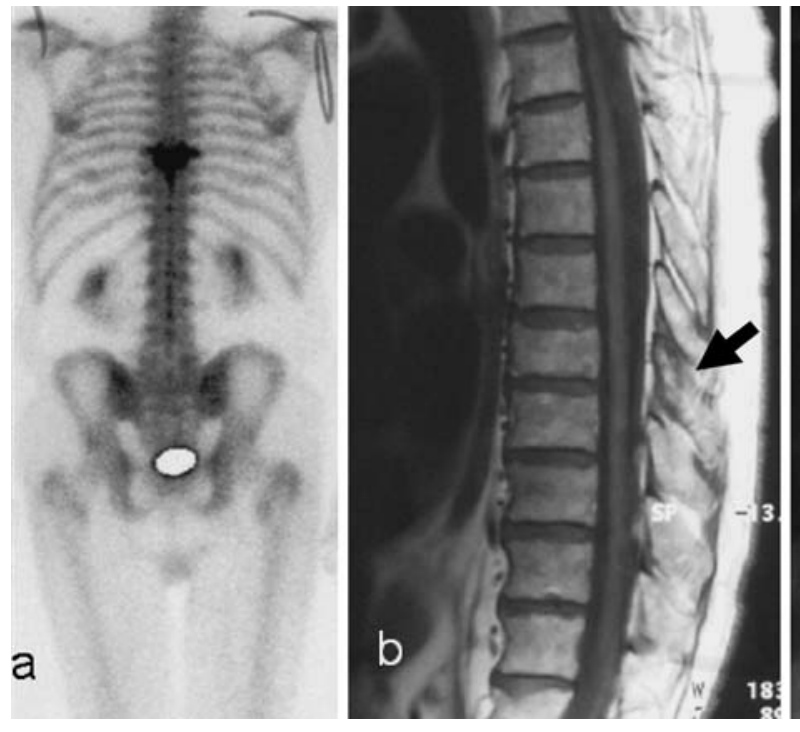

Fig. 10 a Initial scintigraphy for back pain demonstrates isolated increased uptake at a single vertebral level (T8). On initial inspection sagittal b T1-weighted and $\mathbf{c}$ T2-weighted MR images do not show any abnormality of the vertebral body. There is, though, some abnormal low signal from the posterior elements (black arrow). The
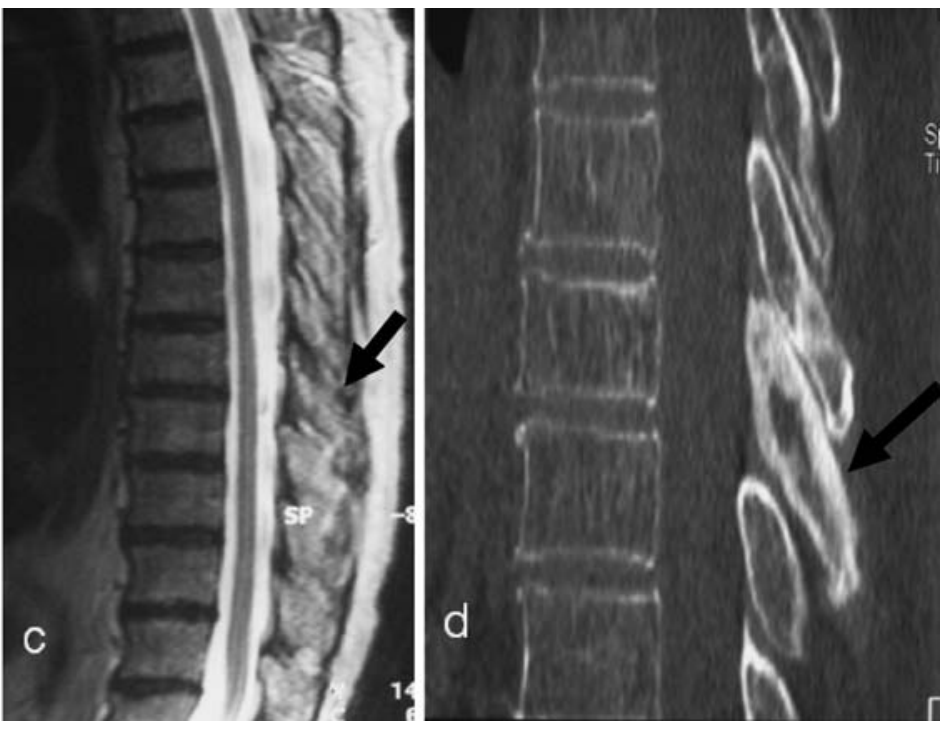

diagnosis is still not clear. d However, a CT scan demonstrates the clear posterior vertebral (black arrow) sclerotic changes consistent with PD. Even on CT there are only minimal changes in the vertebral body 

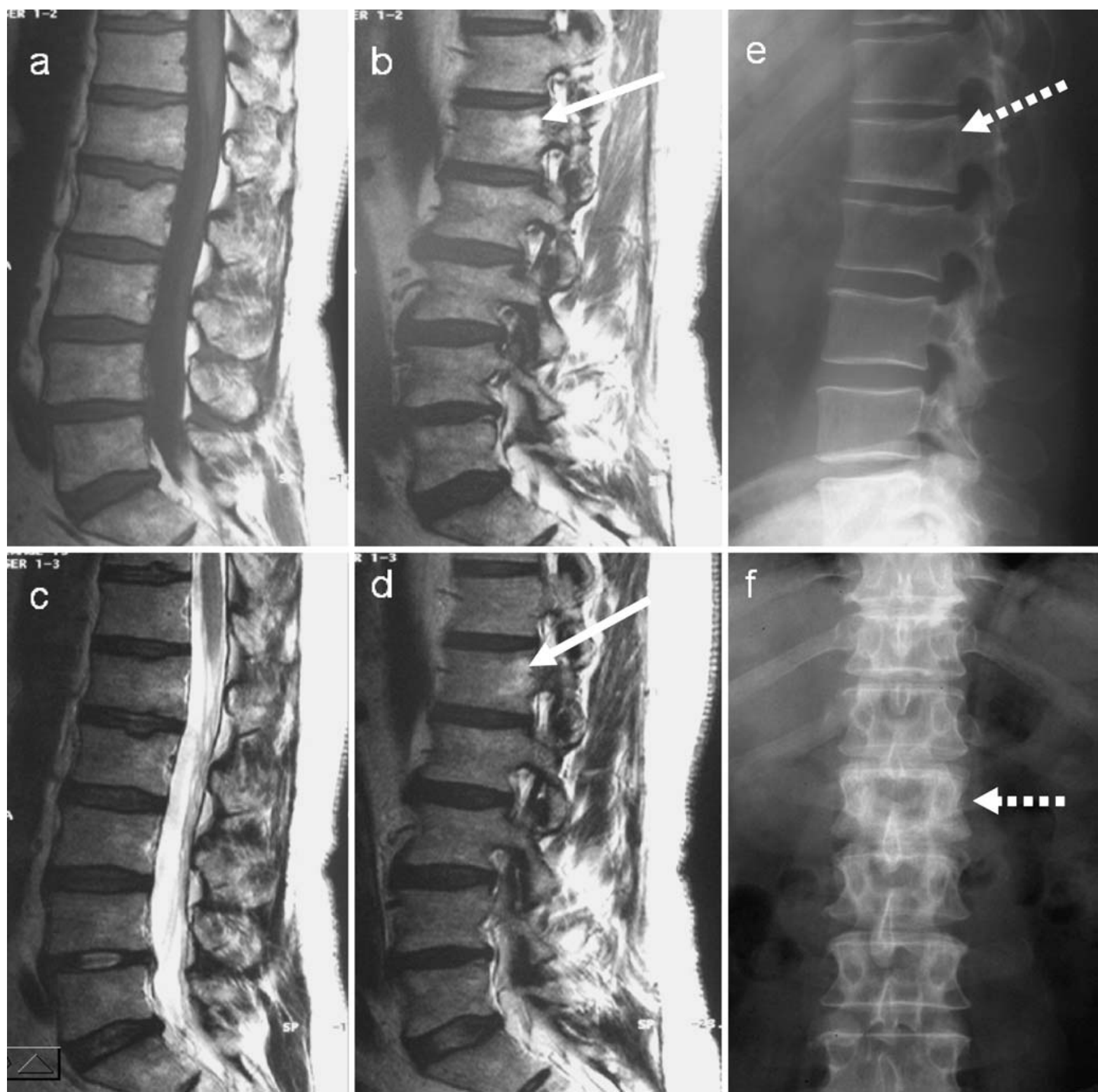

Fig. 11 On initial examination, a sagittal and b parasagittal T1weighted, $\mathbf{c}$ sagittal and $\mathbf{d}$ parasagittal T2-weighted MR images of the lumbar spine do not demonstrate any obvious abnormality. e, f The radiographs, however, show classic pagetic changes of the L1 vertebra

(dashed arrows) including vertebral expansion, sclerosis and cortical thickening. Review of the MRI shows some minor increased signal in the expanded L1 vertebral body on both T1 and T2 parasagittal images, suggestive of fatty marrow change (white arrows)

appearance of the bone marrow, while the intervening trabecular bone is affected. For this reason, vigilance in recognising subtle signs like minor antero-posterior vertebral expansion and minimal cortical thickening is necessary as the signal characteristics within the centre of the vertebra may be entirely normal. MRI should be complemented by radiographs and $\mathrm{CT}$ in these instances (Figs. 10, 11, 12). PD is fundamentally a bone disorder, where the bone marrow may or may not be involved, showing areas of sclerosis, fibrosis, increased vascularity, residual haematopoiesis and fatty marrow replacement, resulting in a wide spectrum of MR signal features. For this reason, all these described MR findings need the comparison of radiographs and $\mathrm{CT}$ images, because only these imaging modalities are actually capable of showing the specific and pathognomonic bony changes of PD. The aim of the integration of different 
Fig. 12 a T1-weighted, b T2weighted sagittal images of the lumbar spine demonstrate no marrow abnormality. There is only a subtle antero-posterior expansion of the L2 and L4. The diagnosis in these patients can be missed on initial MRI.

c Lateral radiograph of the lumbar spine demonstrates the classic pagetic changes including vertebral expansion, trabecular hypertrophy and cortical thickening in L2 and L4. There is an incidental non-pagetic vertebral compression at L1. There is again preservation of the fat signal within the vertebrae involved in $\mathrm{PD}$
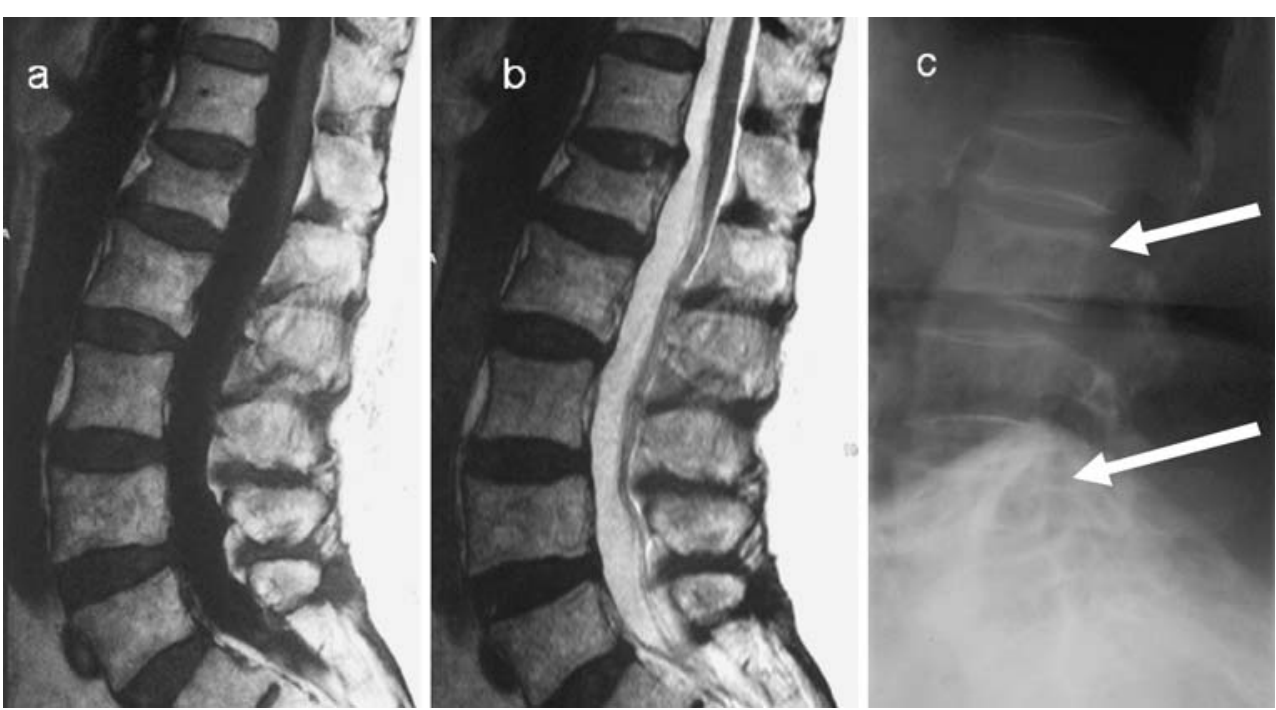

techniques is to make a correct diagnosis and avoid unnecessary biopsy.

\section{Pathological complications}

Pagetic bone is structurally weak. Despite this, the involved vertebral body and posterior neural arch still have to fulfil the biomechanical role they were designed for. The disease will alter the normal metabolic function in the bone while biomechanical forces in turn modify further the metabolic and structural changes that arise. Various clinical complications can occur secondary to vertebral PD resulting in back pain, spinal stenosis and neural dysfunction. Whilst each of these clinical symptoms can be caused by a variety of pagetic complications, it has to be stressed that PD and its complications can be entirely asymptomatic[21]. Moreover, the symptoms could be due to other coexisting spinal disorders.

Back pain is the most common clinical symptom associated with PD of the spine (Table 1). However, not all patients with PD of the spine are symptomatic [21]. Back pain in PD is due either to the disease itself or to the occurrence of different complications (Table 1). Back pain due to the PD itself is caused by an increased blood flow and modelling/remodelling process associated with the vertebral involvement including periosteal stretching and micro-fractures. In general, pagetic pain is a deep, dull ache or pain in the back that is unrelated to activity and not relieved by rest or non-steroidal anti-inflammatory medication. This pain is different from mechanical pain, which improves with rest and worsens with activity or a stressful posture of the back. It is also different from arthritic pain, characterized by aching and stiffness that is relieved by walking or by anti-inflammatory medication [24]. Between 11 and $54 \%[5,55]$ of pagetic patients present with pain. In
$24 \%$ of cases, back pain is due to PD itself $[5,8,24]$. In $50 \%$ of cases, it is due mainly to other complicating factors including fracture, spinal stenosis and facet arthropathy; less commonly it is due to spondylolysis with or without spondylolisthesis and discal involvement [26]. Another study found $88 \%$ of cases with back pain related to coexisting PD and osteoarthritis of the spine versus $12 \%$ of patients with pain attributed only to PD [56]. No particular difference in pain has been seen in multilevel involvement compared with single level involvement [24].

Spinal stenosis in PD of the spine has a prevalence of $33 \%$ of cases (Table 2) [5]. It is graded as mild if it is just perceptible, moderate if the area of the spinal canal is reduced by less than $50 \%$ and severe if that area is reduced by more than $50 \%$ [24, 25]. Spinal stenosis can present clinically as back pain and/or neurological dysfunction, as a consequence of cord (Figs. 8, 13) or nerve root compression. In some cases, spinal stenosis is not associated with back pain. Patients with severe stenosis seen on imaging can present without clinical symptoms and patients with mild or moderate stenosis can present with back pain [24]. This is possibly explained by the adaptability of the thecal sac and its neural elements to severe spinal stenosis without significant loss of function [5, 24]. The proportion of symptomatic patients with spinal stenosis ranges from $26 \%$

Table 1 Causes of back pain in Paget's disease 
Table 2 Causes of neural dysfunction in Paget's disease

Posterior expansion of the vertebral body

Posterior neural arch expansion

Facet joint arthritis/overgrowth

Ligament ossification

Spondylolisthesis

Fracture retropulsion

Extra-osseous involvement—PD, haematopoiesis, "pseudosarcoma", malignancy

"Arterial steal" syndrome

[57] to $33 \%$ [5]. Seventy-five per cent of these cases present with pain, but without neurological dysfunction [25]. Expanded pagetic bone involving all vertebral components (vertebral body, neural arch and facet joints) is the commonest cause of spinal stenosis (Fig. 13). It was reported by Wyllie in 1923 [58]. It is a consequence of a disturbance in the bone remodelling process, leading to a subsequent decrease in the spinal canal size $[5,24]$. Less

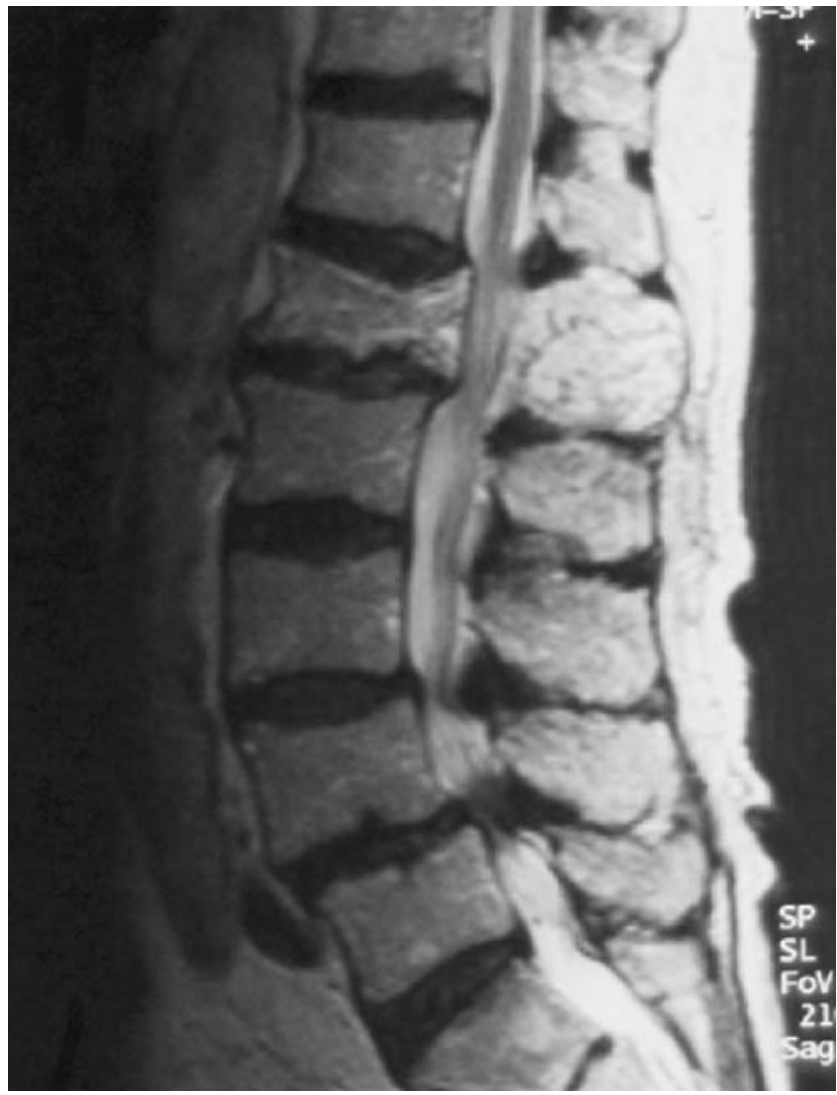

Fig. 13 Sagittal T2-weighted MR image demonstrates cauda equina compression at the L1 level due to pagetic enlargement of the whole vertebra. Note the stenosis caused by expansion of both the vertebral body and posterior elements. Degenerative spondylolisthesis and stenosis at L4/L5 is noted frequently, the stenosis can be due solely to expansion of the neural arch associated with the growth of pagetic bone involving the facets [8].

Spinal stenosis in Paget's disease has the unique radiographic feature of widening of the interpediculate distance on the antero-posterior view, with expansion of the vertebral body on the lateral view. CT is very useful for assessing the contribution of the facets and neural arch to the stenosis, not seen well on radiographs (Fig. 14). CT also helps to assess the location of the expanded bone to determine if the stenosis is central or lateral and to assess the severity of the stenosis. In cases in which cord compression due to the spinal stenosis is suspected, the diagnostic tier has to be completed by performing an MRI scan (Figs. 8, 13) [8, 24, 59]. Axial and sagittal images demonstrate the bone abnormalities, but they can also show myelomalacia in the spinal cord. The sagittal T2-weighted images show the pagetic bone compressing the cord with no evidence of normal CSF surrounding the cord. The axial images show the asymmetry or deformation in shape of the cord compressed by the expanded bone. Areas of myelomalacia demonstrate low cord signal on T1-weighted images and high signal on T2-weighted and STIR images, at the same level as the expanded pagetic bone.

Neural dysfunction can be due to spinal stenosis (33\%) $[24,60]$, more frequently with thoracic spine involvement and less commonly with cervical spine involvement [61]. The less frequent neural involvement in lumbar spine involvement is due to the relatively capacious spinal canal in the lumbar region $[5,57,62]$. Although the pagetic process itself, together with compressive effects from the expanding bone, can give rise to symptoms and signs, other complications may develop and contribute to the symptoms complex of neural dysfunction (Table 2). Patients presenting with neurogenic pain due to cord compression by expanded pagetic bone (Fig. 20) can also respond well to medical treatment with calcitonin and bisphosphonates [63]. Surgical decompression is rarely necessary in cord compression as stenosis and neural dysfunction in PD may respond to medical treatment alone [5]. The "arterial steal phenomenon" is another factor contributing to neural dysfunction. This is described as a deprivation of blood supply to the spinal cord due to the preferential blood flow of the pagetic vertebra (Fig. 15) [64]. It is classified as a non-compressive spinal cord dysfunction and not directly related to pagetic bone growth and it can respond very well to treatment with calcitonin [64-66].

\section{Compression fracture}

Compression fracture of the vertebral body is the commonest complication in PD of the spine and usually presents with sudden onset of back pain (Fig. 16). It occurs more 
Fig. 14 Post-myelographic lateral lumbar spine a radiograph and $\mathbf{b}$ axial CT scan demonstrate spinal block at the L1 vertebral level, which is pagetic. Note the severe degree of spinal stenosis despite the apparent increase in the interpedicular distance on the axial $\mathrm{CT}$ image
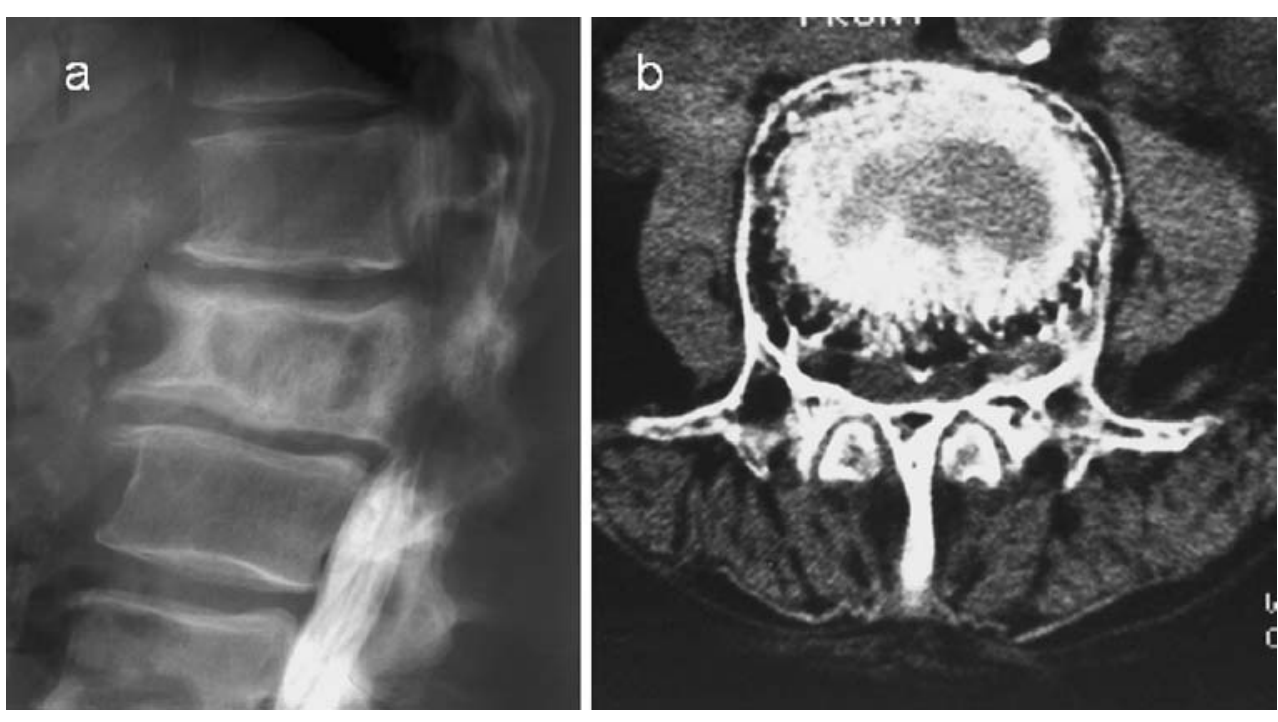

frequently in the lumbar spine [59], and rarely in the sacrum [59], the coccyx [67] and the odontoid peg.

Para-vertebral swelling can be seen as an indirect sign of the vertebral fracture in the acute phase. The fracture line itself is best seen on CT with sagittal reconstructions.

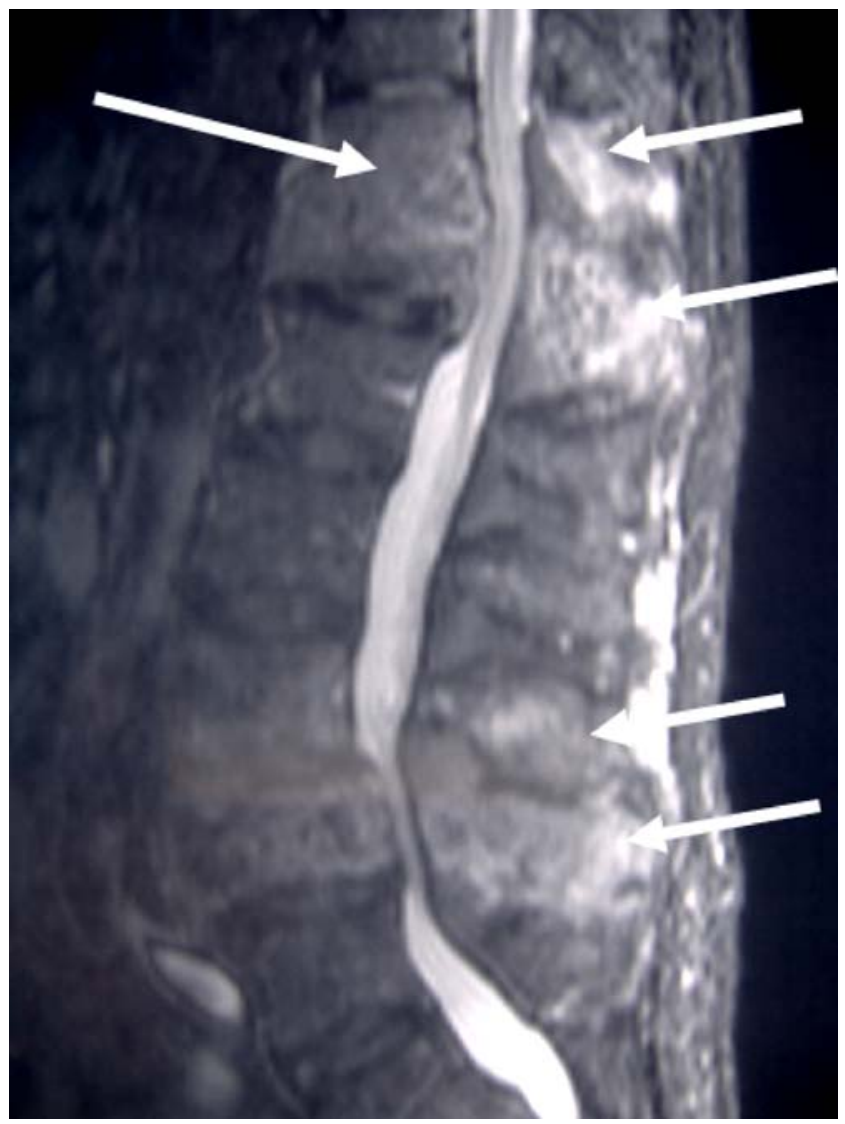

Fig. 15 Sagittal fat suppressed T1-weighted image after gadoliniumDTPA administration in the same patient as in Fig. 8 demonstrates intense enhancement at both the T12/L1 and the L3/L4 levels (arrows). The enhancement in part reflects increased blood supply to the vertebra
Vertebral fracture can also contribute to the pain related to spinal stenosis by two mechanisms: posterior vertebral body wall bulging and retropulsion (Fig. 16) of a bone fragment into the spinal canal $[8,68]$, and cord compression. This can be recognised on radiographs in the lateral view and is associated with a decrease in the spinal canal size, but CT demonstrates this better.

The fractured vertebra in PD sometimes appears osteopenic on radiographs. This could be due to a fracture occurring in the lytic phase of PD. However, as described earlier, it is unusual to see the lytic phase of PD in the spine. The osteopenia is most likely due to fracture-induced osteolysis. MRI can also contribute to the diagnosis of a compression fracture, even if its findings are not specific. The fracture line is seen as a linear or curvilinear low signal on T1-weighted images and high signal on T2-weighted and STIR images. Oedema surrounding the fracture can be an indirect sign. It is seen as high signal on inversion recovery and T2-weighted images and low signal on T1weighted images. When the fracture is not recent, the signal on the MRI scan will be low on both T1- and T2-weighted images because of the sclerosis of the bone. In general, diffusion weighted imaging can help to differentiate osteoporotic from malignant vertebral body collapse [69]. It is not yet known if benign fracture in PD can be mistaken for a malignant compression on diffusion weighted imaging given the associated underlying marrow changes prior to the occurrence of the fracture.

\section{Facet joint arthropathy}

Facet joint involvement can cause back pain, lateral spinal stenosis and neural dysfunction. Facet involvement can lead to facet joint arthropathy due to two mechanisms. One is the direct extension of PD into the articular cartilage similar to that seen in large synovial joints and the intervertebral 
Fig. 16 Lateral and anteroposterior radiograph of the lumbar spine demonstrates severe compression of a pagetic L3 vertebra with retropulsion into the spinal canal. Note the increased interpediculate distance as a hallmark of PD
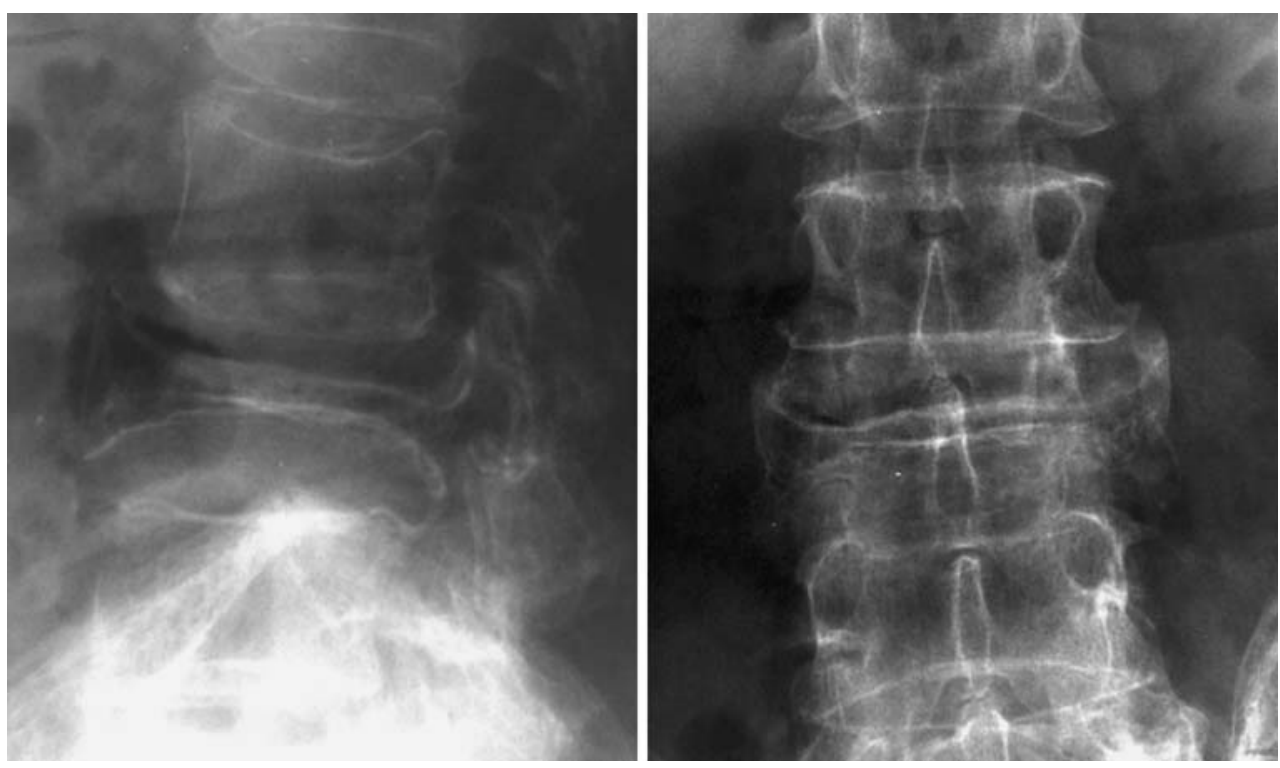

disc [26], the other is the pagetic involvement of the facets leading to expansion of the facet and resultant incongruity with the apposing uninvolved facet (Fig. 9). Facet joint arthropathy was noted in 17 out of 21 symptomatic patients with back pain in one study [25]. This gives rise to mechanical stress and early degenerative changes in the facet joint. This is one of the most important factors in back pain and also contributes to spinal stenosis. The spinal canal stenosis associated with facet joint arthropathy is typically lateral and can result in nerve root compression [5]. Patients with severe arthropathy often have symptoms of spinal stenosis, but they can be asymptomatic [24, 25]. Compared with radiography, CT gives a clearer depiction of facet joint changes (Fig. 9), showing the loss of articular space, the destruction of cartilage associated with subchon- dral erosion and articular incongruity (Fig. 9) [5, 26, 70]. Facet joint arthropathy may eventually lead to ankylosis of the articular space [25]. MR imaging can underestimate the bony changes associated with the facet involvement.

\section{Spondylolysis and spondylolisthesis}

Back pain may be also due to unilateral or bilateral spondylolysis if the pars interarticularis is involved in PD. $\mathrm{PD}$, due to the associated modelling/remodelling activity, results in an increased susceptibility to insufficiency fractures. A lateral radiograph may demonstrate the typical spondylolysis (Fig. 17). However, due to the associated PD and sclerosis, this can be difficult to appreciate. CT is the best modality to detect this. Underestimation of this
Fig. 17 Lateral radiographs in two different patients with PD showing two different mechanisms of spondylolisthesis: a spondylolytic (arrow) spondylolisthesis; b degenerative spondylolisthesis
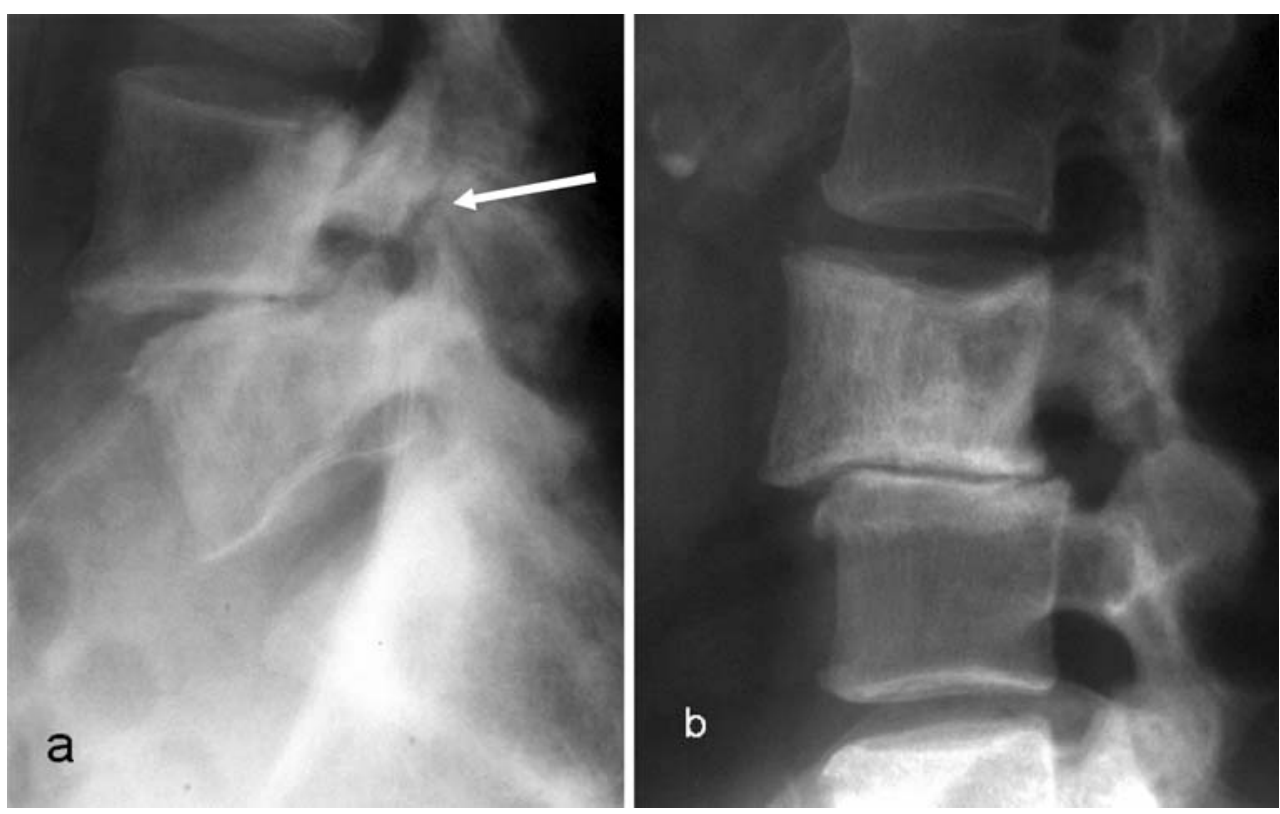
Fig. 18 Disc involvement. Serial radiographs 2 years apart in the same patient demonstrate progressive involvement of the L4/L5 intervertebral disc in

Paget's disease of the L5

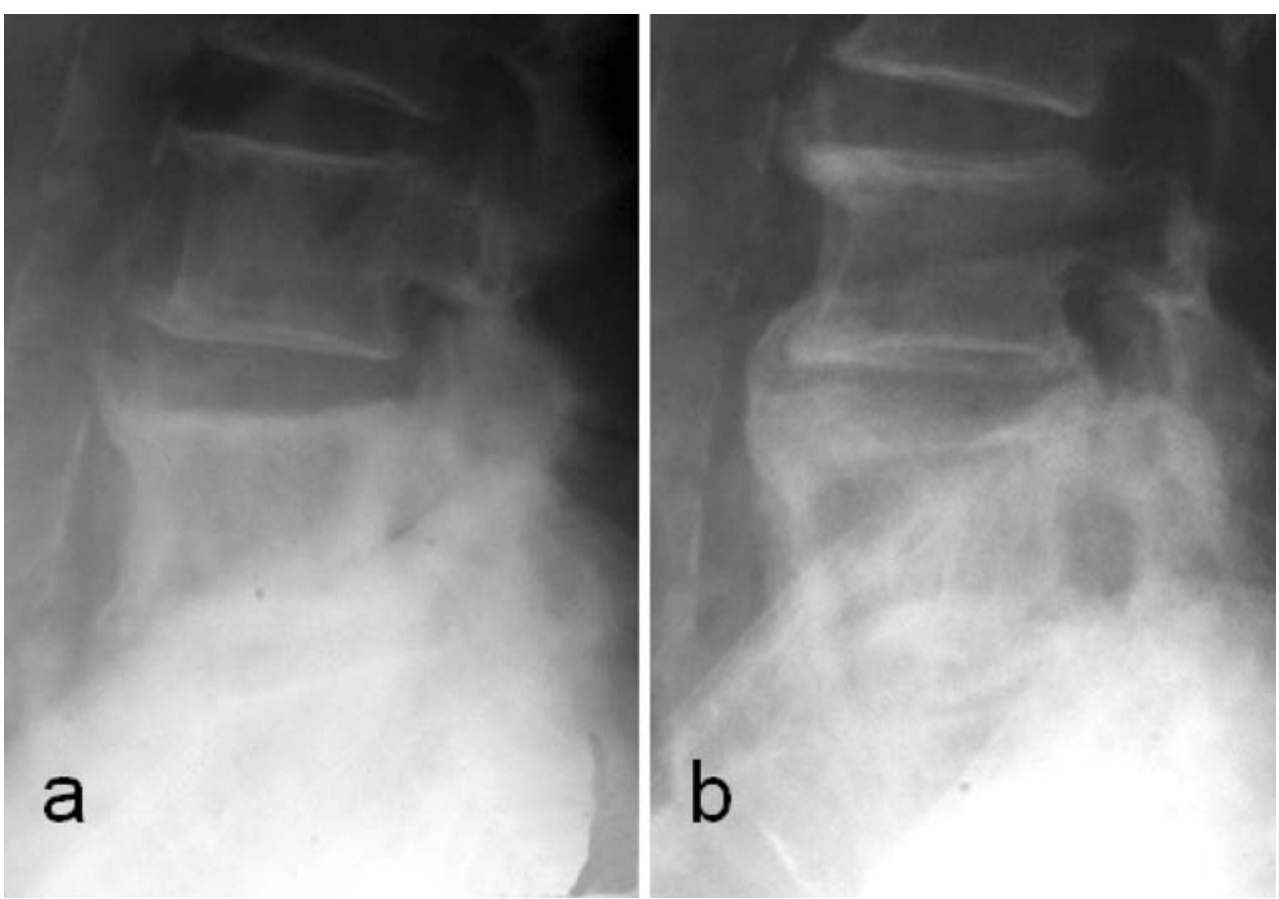

complication on radiographs and the relatively limited use of cross-sectional imaging in PD may be the reason for the under-reporting of this condition.

Spondylolisthesis in PD can be due to either spondylolysis or facet joint degeneration (Fig. 17). It is important to differentiate between the two entities. The degenerative spondylolisthesis results in spinal stenosis and neural dysfunction. The lateral radiograph is quite useful for detecting spondylolisthesis and to establish its grade and severity. However, this can be underestimated if the vertebral alignment is not assessed carefully. An enlarged vertebra due to PD may slip anteriorly over a normal vertebra, but the posterior vertebral body alignment may still be preserved due to the posterior expansion. The assessment of the posterior neural arch alignment, however, will reveal the subtle slip in these cases. The standard lateral radiograph can be complemented by dynamic views in flexion and extension, which can reveal the presence of spondylolisthesis under stress.
Fig. 19 Extra-osseous Paget's disease. a Sagittal CT reconstruction and $\mathbf{b}$ T1-weighted MR sagittal image demonstrate anterior longitudinal ligament ossification (white arrows). c, d Axial CT sections demonstrate ossification in the ligamentum flavum due to extraosseous PD (black arrows) in a different patient. e Antero-posterior radiograph in another patient demonstrates paravertebral soft tissue swelling (dashed arrows) producing the "pseudo-sarcoma" appearance
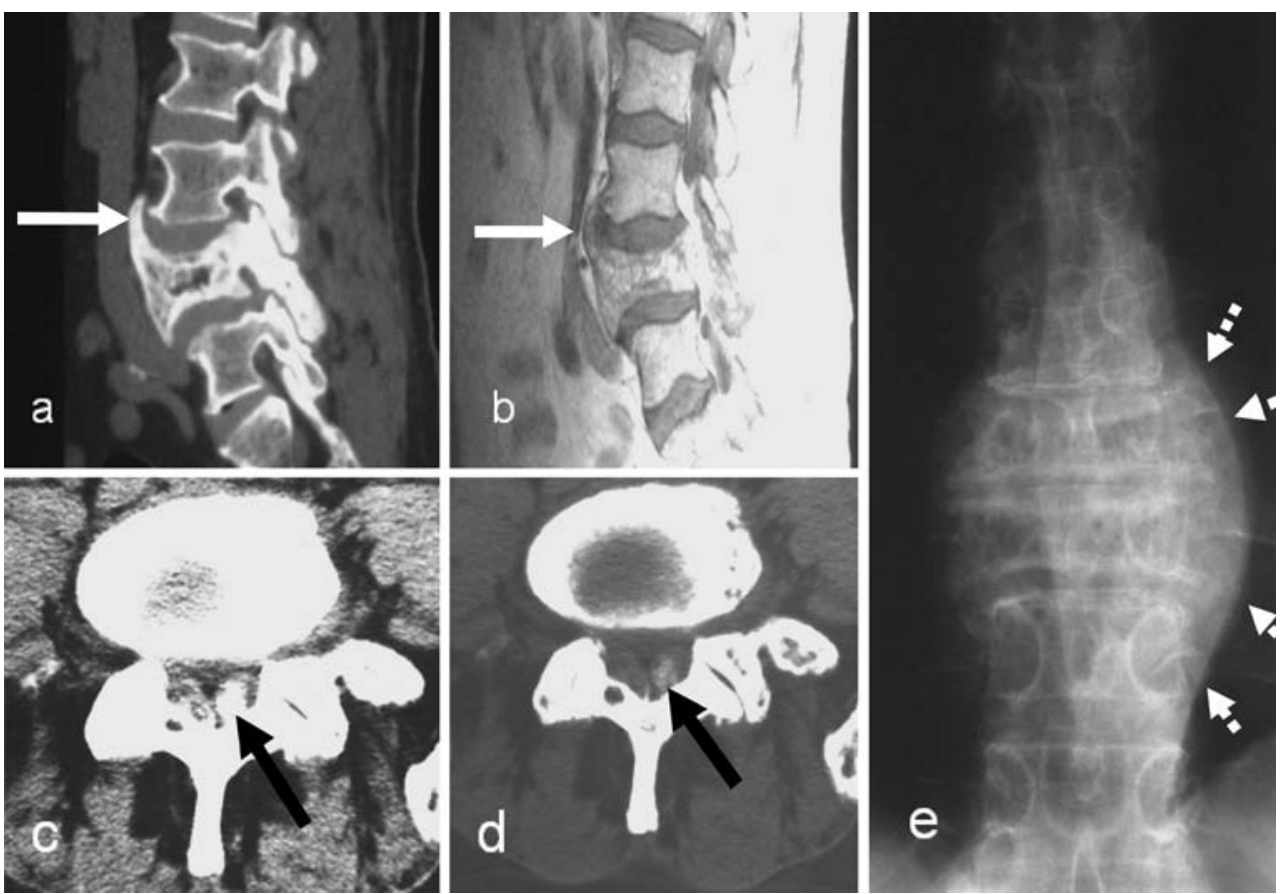
Table 3 Causes of paravertebral swelling in Paget's disease

\section{Extra-osseous extension}

Fracture haematoma

Extra-medullary haematopoiesis

Paget's sarcoma/other tumours

Paget's pseudosarcoma

Spondylolisthesis, and particularly spondylolysis, can be confirmed on CT with sagittal reconstruction images.

Intervertebral disc involvement

Paget's disease can involve the intervertebral disc and cause intervertebral disc degeneration. The incidence of direct intradiscal transgression is about $10.7 \%$ [26]. In this study, $67 \%$ of patients with disc involvement presented with pain. Twenty-two percent were asymptomatic. Therefore, disc involvement can remain asymptomatic. Some studies describe the presence of para-vertebral soft tissue involvement without specific comment on the discal invasion by PD $[45,68]$. PD transgressing the intervertebral disc occurs more often in the lumbar spine than in the thoracic and cervical spine. The mechanism is not very clear. Intervertebral disc degeneration can be caused mainly by the mechanical stress induced by asymmetry at the end plate attachment of annulus fibrosis between a pagetic and a normal vertebra, and also by direct invasion of the disc space by the pagetic process. Aggressive pagetic invasion at the disco-vertebral junction leads to pagetic tissue replacement of the cartilage end-plate and subsequently of the intervertebral disc. The direct resorption of the disc tissue with subsequent pagetic bone replacement in the disc is the most likely explanation [26]. PD can then invade the adjoining vertebra across the disc space. This can also occur by direct extension of PD along large pre-existing degenerative bridging osteophytes [26]. Radiological investigations in disc involvement show progressive disc space narrowing, loss of definition of the adjacent end-plates, sometimes indistinguishable from spondylodiscitis, and large degenerative osteophytes involved in PD (Figs. 8, 18). Intervertebral disc involvement can eventually lead to pagetic vertebral ankylosis (PVA) with an incidence of 4.4\% [26]. Ankylosis is commoner in men, affects the thoracic spine in over $50 \%$ of cases [71] and is usually asymptomatic. The fusion between the vertebral bodies is easily appreciated as being due to Pagetic changes. The mechanisms that promote intervertebral disc involvement in $\mathrm{PD}$ are also in play when extra-osseous involvement of the spinal ligaments and para-vertebral tissues is seen (Fig. 19).
Fig. 20 Vertebral metastasis from colon carcinoma. Sagittal a T1- and b T2-weighted MR images demonstrate metastasis in L2 and L4 vertebral bodies seen as discrete lesions (white arrows) with low signal on T1and high signal on T2-weighted images. A further epidural lesion (black arrow) is seen in the spinal canal posteriorly at L3. Note the pagetic changes with expansion of L2 and L3 vertebral bodies
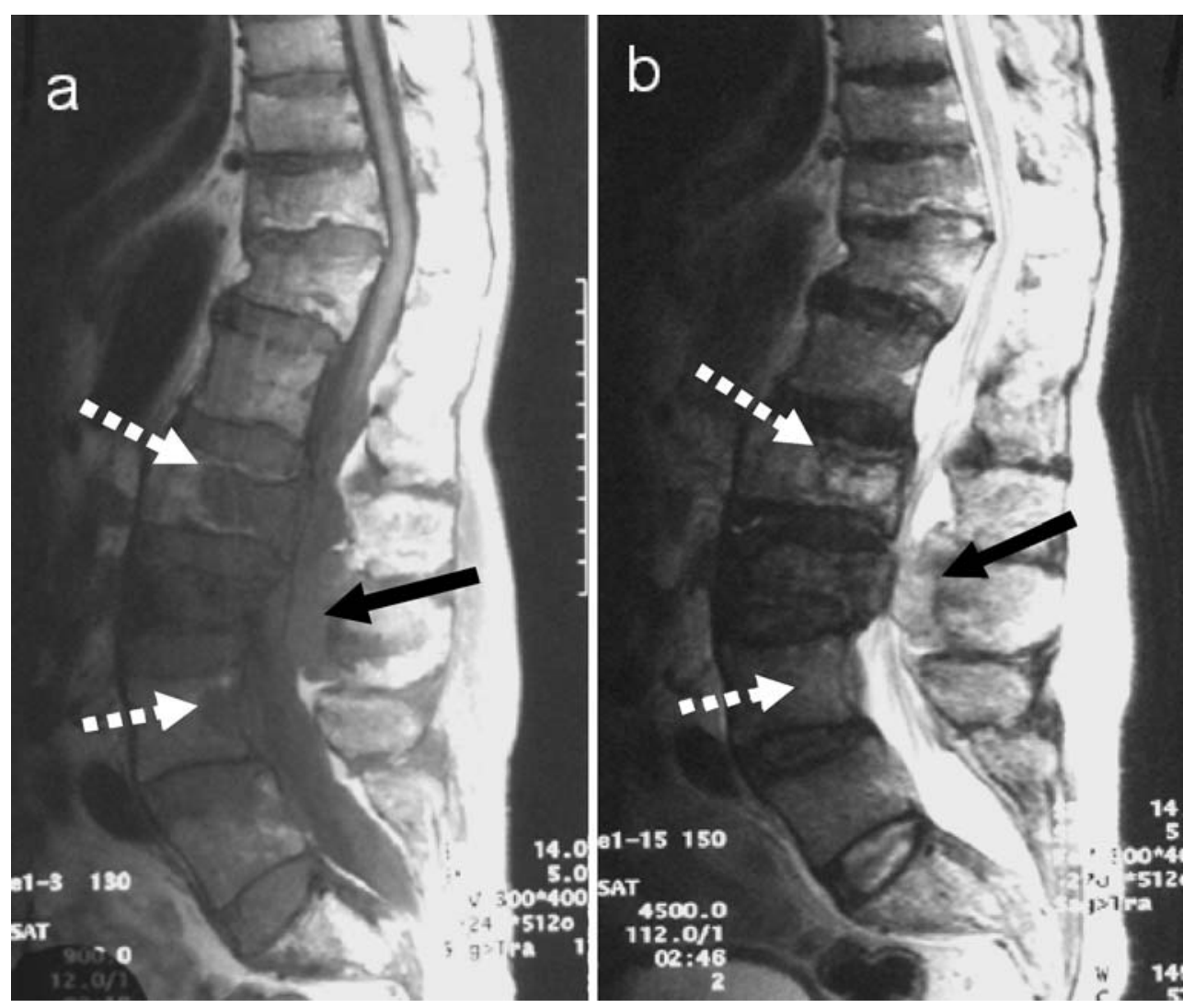
Neoplastic transformation

Neoplastic transformation in pagetic bone is very rare in the spine $(0.7 \%)[5,8,24,72]$ and represents only $7 \%$ [73] of all sarcomatous degeneration in PD. It can present with back pain. Benign and malignant bone neoplasms can complicate Paget's disease. The majority of malignant transformations are osteosarcomas. They seem to be related to one or two genes on the chromosome 18q $[5,74,75]$.

Radiologically, this is seen on radiographs and CT images as a lytic lesion characterised by an aggressive pattern on a background of typical PD. It can be very difficult to diagnose this lesion on the radiographs because of the overlapping pagetic changes in the bone. However, as described earlier, it is unusual to see the lytic phase of PD in the absence of other complicating factors like a fracture. A para-vertebral soft tissue mass should always be regarded as possible neoplastic transformation associated with vertebral Paget's disease, but more frequently is due to benign causes (Table 3). On MR axial and sagittal images the sarcomatous degeneration appears as a mass with irregular edges showing low signal on T1- and inhomogeneous high signal on T2-weighted images [8]. The preservation of the medullary fat signal on T1-weighted images excludes malignant degeneration and can be an extremely useful sign [54]. It usually shows inhomogeneous contrast enhancement after gadolinium administration because of its solid structure with internal vascularity. The other differential diagnosis to be considered is extramedullary haematopoiesis. Less common is the "pseudosarcoma" appearance characterised by extra-cortical periosteal bone expansion or by a bulky juxta-cortical soft tissue mass similar in its characteristics on imaging to sarcomatous degeneration (Fig. 19) [11, 76, 77]. Malignant transformation can contribute to spinal stenosis [5]. For this reason the radiological assessment is not only focussed on the presence of a malignant mass, but also on the presence of cord compression, well documented on sagittal T1- and T2weighted MR images. The spine is a common site for metastatic disease and the secondary deposits may also involve bones previously involved in Paget's disease (Fig. 20). A biopsy may be necessary to differentiate among these various entities.

\section{Conclusion}

Recognition of the imaging manifestations of spinal PD and the potential clinical complications enables accurate assessment of patients prior to appropriate management. This knowledge should allow subtle PD to be identified on imaging when this is not suspected. This is especially relevant to MRI, as it has become the imaging modality of choice for investigating the spine. Patients presenting with back pain and spinal stenosis have to be assessed for pagetic complications before attributing the symptomatology to the disease itself.

\section{References}

1. Collins DH. Paget's disease of bone; incidence and subclinical forms. Lancet 1956; 271 6933: 51-57.

2. Schmorl G. Über Osteitis deformans Paget. Virchows Arch Pathol Anat Physiol 1932; 238: 694-751.

3. Maldague B, Malghem J. Dynamic radiologic patterns of Paget's disease of bone. Clin Orthop Relat Res 1987; 217: 126-151.

4. Basle MF, Rebel A, Fournier JG, Russell WC, Malkani K. On the trail of paramyxoviruses in Paget's disease of bone. Clin Orthop Relat Res 1987; 217: 9-15.

5. Hadjipavlou AG, Gaitanis LN, Katonis PG, Lander P. Paget's disease of the spine and its management. Eur Spine J 2001; 10 5: 370-384.

6. Langston AL, Ralston SH. Management of Paget's disease of bone. Rheumatology (Oxford) 2004; 43 8: 955-959.

7. Mirra JM, Brien EW, Tehranzadeh J. Paget's disease of bone: review with emphasis on radiologic features. I. Skeletal Radiol 1995; 24 3: 163-171.

8. Saifuddin A, Hassan A. Paget's disease of the spine: unusual features and complications. Clin Radiol 2003; 58 2: 102-111.

9. Hadjipavlou A, Begin LR, Abitbol JJ. [Morphological, histochemical and ultrastructural observations concerning in vitro cell cultures of pagetic and normal bone]. Union Med Can 1986; 115 10: 746-750.

10. Hadjipavlou AG, Katonis PG, Tzermiadianos MN, Tsoukas GM, Sapkas G. Principles of management of osteometabolic disorders affecting the aging spine. Eur Spine J 2003; 12 Suppl 2: S113-S131.

11. Haslam SI, Van Hul W, Morales-Piga A, et al. Paget's disease of bone: evidence for a susceptibility locus on chromosome 18q and for genetic heterogeneity. J Bone Miner Res 1998; 13 6: 911-917.

12. Hocking L, Slee F, Haslam SI, et al. Familial Paget's disease of bone: patterns of inheritance and frequency of linkage to chromosome 18q. Bone 2000; 26 6: 577-580.

13. Khan SA, Brennan P, Newman J, Gray RE, McCloskey EV, Kanis JA. Paget's disease of bone and unvaccinated dogs. Bone 1996; 19 1: 47-50.

14. Lopez-Abente G, Morales-Piga A, Elena-Ibanez A, Rey-Rey JS, Corres-Gonzalez J. Cattle, pets, and Paget's disease of bone. Epidemiology 1997; 8 3: 247-251.

15. Rasmussen H, Bordier P. The cellular basis of metabolic bone disease. N Engl J Med 1973; 289 1: 25-32.

16. Cooper C, Schafheutle K, Dennison E, Kellingray S, Guyer P, Barker D. The epidemiology of Paget's disease in Britain: is the prevalence decreasing? J Bone Miner Res 1999; 14 2: 192-197.

17. Van Staa TP, Selby P, Leufkens HG, Lyles K, Sprafka JM, Cooper C. Incidence and natural history of Paget's disease of bone in England and Wales. J Bone Miner Res 2002; 17 3: 465-471.

18. Cundy T. Is Paget's disease of bone disappearing? Skeletal Radiol 2006; 35 6: 350-351.

19. Cundy T, McAnulty K, Wattie D, Gamble G, Rutland M, Ibbertson HK. Evidence for secular change in Paget's disease. Bone 1997; 20 1: 69-71.

20. Cundy HR, Gamble G, Wattie D, Rutland M, Cundy T. Paget's disease of bone in New Zealand: continued decline in disease severity. Calcif Tissue Int 2004; 75 5: 358-364.

21. Altman RD, Brown M, Gargano F. Low back pain in Paget's disease of bone. Clin Orthop Relat Res 1987; 217: 152-161. 
22. Danais S, Hadjipavlou A. [Comparative scientific study of lesions of bone and bone marrow in Paget's disease]. Union Med Can 1977; 106 8: 1100-1109.

23. Meunier PJ, Salson C, Mathieu L, et al. Skeletal distribution and biochemical parameters of Paget's disease. Clin Orthop Relat Res 1987; 217: 37-44.

24. Hadjipavlou A, Lander P, Srolovitz H. Pagetic arthritis. Pathophysiology and management. Clin Orthop Relat Res 1986; 208: 15-19.

25. Zlatkin MB, Lander PH, Hadjipavlou AG, Levine JS. Paget disease of the spine: CT with clinical correlation. Radiology 1986; 160 1: 155-159.

26. Lander P, Hadjipavlou A. Intradiscal invasion of Paget's disease of the spine. Spine 1991; 16 1: 46-51.

27. Milgram JW. Radiographical and pathological assessment of the activity of Paget's disease of bone. Clin Orthop Relat Res 1977; 127: 43-54.

28. Vande Berg BC, Malghem J, Lecouvet FE, Maldague B. Magnetic resonance appearance of uncomplicated Paget's disease of bone. Semin Musculoskelet Radiol 2001; 5 1: 69-77.

29. Epstein BS. The spine: a radiologic text and atlas, 4th edn. Lea \& Febiger, Philadelphia, 1976.

30. Siris ES. Goals of treatment for Paget's disease of bone. J Bone Miner Res 1999; 14 Suppl 2: 49-52.

31. Siris ES. Paget's disease of bone: treatment philosophy for the twenty-first century. Bone 1999; 245 Suppl: 55S-56S.

32. Lander PH, Hadjipavlou AG. A dynamic classification of Paget's disease. J Bone Joint Surg Br 1986; 68 3: 431-438.

33. Guyer PB, Shepherd DF. Paget's disease of the lumbar spine. Br J Radiol 1980; 53 628: 286-288.

34. Brown HP, LaRocca H, Wickstrom JK. Paget's disease of the atlas and axis. J Bone Joint Surg Am 1971; 53 7: 1441-1444.

35. Hepple S, Getty JM, Douglas DL. Paget's disease and odontoid peg fracture: a case report. Injury 1998; 29 4: 323-325.

36. Graham TS. The ivory vertebra sign. Radiology 2005; 235 2: 614-615.

37. Schreiber MH, Richardson GA. Paget's disease confined to one lumbar vertebra. Am J Roentgenol Radium Ther Nucl Med 1963; 90: 1271-1276.

38. Dennis JM. The solitary dense vertebral body. Radiology 1961; 77: 618-621.

39. Harris DJ, Fornasier VL. An ivory vertebra: monostotic Paget's disease of bone. Clin Orthop Relat Res 1978; 136: 173-175.

40. Ochsner HC, Moser RH. Ivory vertebra. Am J Roentgenol 1933; 29: 635-637.

41. Souques A, Lafourcade, Terris. "Vertebra d'ivoire" dans un cas de cancer metastatique de la colonne vertebrale. Rev Neurol 1925; 32: 3-10.

42. Sprecher S, Steinberg R, Lichtenstein D, Witt KM, Barginear M. Magnetic resonance imaging presentation of lytic Paget's disease of the cervical spine. J Bone Miner Res 2002; 17 11: 1929-1930.

43. Steinbach LS, Johnston JO. Case report 777. Osteolytic Paget's disease of the fifth lumbar vertebra. Skeletal Radiol 1993; 22 3: 203-205.

44. Rosen MA, Wesolowski DP, Herkowitz HN. Osteolytic monostotic Paget's disease of the axis. A case report. Spine 1988; 131 : 125-127.

45. Clarke PR, Williams HI. Ossification in extradural fat in Paget's disease of the spine. Br J Surg 1975; 62 7: 571-572.

46. Rotes-Sala D, Monfort J, Solano A, Miralles E, Vila J, Carbonell J. The clover and heart signs in vertebral scintigraphic images are highly specific of Paget's disease of bone. Bone 2004; 34 4: 605-608.

47. Khairi MR, Robb JA, Wellman HN, Johnston CC Jr. Radiographs and scans in diagnosing symptomatic lesions of Paget's disease of bone (osteitis deformans). Geriatrics 1974; 29 12: 49-54.

48. Van Heerden BB. Mickey Mouse sign in Paget's disease. J Nucl Med 1994; 35 5: 924-925.
49. Estrada WN, Kim CK. Paget's disease in a patient with breast cancer. J Nucl Med 1993; 34 7: 1214-1216.

50. Cook GJ, Blake GM, Marsden PK, Cronin B, Fogelman I. Quantification of skeletal kinetic indices in Paget's disease using dynamic $18 \mathrm{~F}$-fluoride positron emission tomography. J Bone Miner Res 2002; 17 5: 854-859.

51. Nguyen BD, Ram PC, Roarke MC. PET/CT imaging of metastatic deposit in vertebral Paget's disease. Clin Nucl Med 2005; 30 5: 359-360.

52. Relea A, Garcia-Urbon MV, Arboleya L, Zamora T. Extramedullary hematopoiesis related to Paget's disease. Eur Radiol 1999; 9 2: 205-207.

53. Hayes CW, Jensen ME, Conway WF. Non-neoplastic lesions of vertebral bodies: findings in magnetic resonance imaging. Radiographics 1989; 9 5: 883-903.

54. Sundaram M, Khanna G, El-Khoury GY. T1-weighted MR imaging for distinguishing large osteolysis of Paget's disease from sarcomatous degeneration. Skeletal Radiol 2001; 30 7: 378383.

55. Altman RD. Musculoskeletal manifestations of Paget's disease of bone. Arthritis Rheum 1980; 23 10: 1121-1127.

56. Altman RD, Bloch DA, Hochberg MC, Murphy WA. Prevalence of pelvic Paget's disease of bone in the United States. J Bone Miner Res 2000; 15 3: 461-465.

57. Hartman JT, Dohn DF. Paget's disease of the spine with cord or nerveroot compression. J Bone Joint Surg Am 1966; 48 6: 1079-1084.

58. Wyllie WG. The occurrence in osteitis deformans of lesions of the central nervous system, with a report of four cases. Brain 1923; 46: 336-351.

59. Boutin RD, Spitz DJ, Newman JS, Lenchik L, Steinbach LS. Complications in Paget disease at MR imaging. Radiology 1998; 209 3: 641-651.

60. Nicholson DA, Roberts T, Sanville PR. Spinal cord compression in Paget's disease due to extradural pagetic ossification. Br J Radiol 1991; 64 765: 864-866.

61. Mawhinney R, Jones R, Worthington BS. Spinal cord compression secondary to Paget's disease of the axis. Br J Radiol 1985; 58 696: 1203-1206.

62. Klenerman L. Cauda equina and spinal cord compression in Paget's disease. J Bone Joint Surg Br 1966; 48 2: 365-370.

63. Wallace E, Wong J, Reid IR. Pamidronate treatment of the neurologic sequelae of pagetic spinal stenosis. Arch Intern Med 1995; 155 16: 1813-1815.

64. Herzberg L, Bayliss E. Spinal-cord syndrome due to non-compressive Paget's disease of bone: a spinal-artery steal phenomenon reversible with calcitonin. Lancet 1980; 2 8184: 13-15.

65. Douglas DL, Duckworth T, Kanis JA, et al. Biochemical and clinical responses to dichloromethylene diphosphonate (Cl2MDP) in Paget's disease of bone. Arthritis Rheum 1980; 23 10: 11851192.

66. Hadjipavlou AG, Tsoukas GM, Siller TN, Danais S, Greenwood F. Combination drug therapy in treatment of Paget's disease of bone: clinical and metabolic response. J Bone Joint Surg Am 1977; 59 8: 1045-1051.

67. Davis DP, Bruffey JD, Rosen P. Coccygeal fracture and Paget's disease presenting as acute cauda equina syndrome. J Emerg Med 1999; 17 2: 251-254.

68. Siegelman SS, Levine SA, Walpin L. Paget's disease with spinal cord compression. Clin Radiol 1968; 19 4: 421-425.

69. Castillo M. Diffusion-weighted imaging of the spine: is it reliable? AJNR Am J Neuroradiol 2003; 24 6: 1251-1253.

70. Merkow RL, Lane JM. Paget's disease of bone. Orthop Clin North Am 1990; 21 1: 171-189.

71. Marcelli C, Yates AJ, Barjon MC, Pansard E, Angelloz-Pessey L, Simon L. Pagetic vertebral ankylosis and diffuse idiopathic skeletal hyperostosis. Spine 1995; 20 4: 454-459. 
72. Hadjipavlou A, Shaffer N, Lander P, Srolovitz H. Pagetic spinal stenosis with extradural pagetoid ossification. A case report. Spine 1988; 13 1: 128-130.

73. Schajowicz F, Santini Araujo E, Berenstein M. Sarcoma complicating Paget's disease of bone. A clinicopathological study of 62 cases. J Bone Joint Surg Br 1983; 65 3: 299-307.

74. Cody JD, Singer FR, Roodman GD, et al. Genetic linkage of Paget disease of the bone to chromosome 18q. Am J Hum Genet 1997; 61 5: 1117-1122.
75. Nellissery MJ, Padalecki SS, Brkanac Z, et al. Evidence for a novel osteosarcoma tumor-suppressor gene in the chromosome 18 region genetically linked with Paget disease of bone. Am J Hum Genet 1998; 63 3: 817-824.

76. Lamovec J, Rener M, Spiler M. Pseudosarcoma in Paget's disease of bone. Ann Diagn Pathol 1999; 3 2: 99-103.

77. Tins BJ, Davies AM, Mangham DC. MR imaging of pseudosarcoma in Paget's disease of bone: a report of two cases. Skeletal Radiol 2001; 30 3: 161-165. 